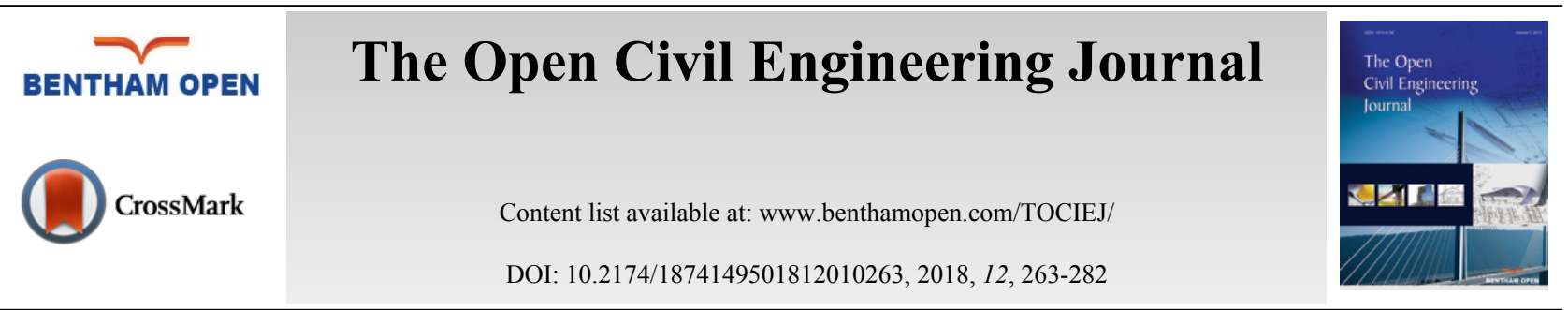

RESEARCH ARTICLE

\title{
Behavior of High Strength Hybrid Reinforced Concrete Deep Beams under Monotonic and Repeated Loading
}

\author{
Sawsan Akram Hassan and Ansam Hassan Mhebs ${ }^{*}$ \\ Civil Engineering Department, Al-Mustansiriayah University, Baghdad, Iraq
}

Received: January 13, 2018

Revised: June 22, 2018

Accepted: July 13, 2018

\begin{abstract}
:
Introduction:

This study presents the experimental and analytical investigation of the behavior of high strength hybrid reinforced concrete deep beams under monotonic and repeated two-point load. The idea of hybrid in this work is different. Two types of concrete were used in beam but not in cross-section. The first type was the Fibrous High Strength Concrete (FHSC) at shear spans for enhancing shear capacity against cracking due to diagonal strut failure (by adding Steel Fiber (SF) in that regions), while the second type was the Conventional High Strength Concrete (CHSC) at the mid-portion between the two strengthened shear spans.
\end{abstract}

\section{Methods:}

The experimental work included the casting and testing of ten deep beams. Five among the beams were tested under monotonic loading (control beams) and other beams were tested under repeated loading at the level of $75 \%$ of ultimate load of control beams. The effect of some selected parameters as the type of load, the hybrid and non-hybrid beams, the compressive strength of concrete $\left(f^{\prime} c\right)$ (normal and high) and the amount of web reinforcement $(\rho w)$ were studied in terms of crack patterns, ultimate load and load versus midspan deflection.

\section{Results and Conclusion:}

From the experimental test results, when beam cast with fibrous with SF of $1 \%$ concrete along entire length, the ultimate load of $10.96 \%$ increased as compared with hybrid beam. And it was observed to increase as much as $32.78 \%$ as compared with beam cast from conventional high strength concrete under monotonic loading. Under repeated loading of $75 \%$ control ultimate load, the ultimate load for beam cast with fibrous concrete along entire length increased as much as $15.32 \%$ as compared with hybrid beam. And it was seen to increase $36.17 \%$ as compared with the beam cast from conventional high strength concrete. The percentage increase in ultimate load of hybrid (SF ratio 1\%) deep beam cast with high strength concrete became $97.3 \%$ as compared with the identical beam cast with normal strength concrete under monotonic loading and $(98.21 \%$ ) under repeated loading (load $75 \%$ control beam load). The percentage increase as ultimate load for hybrid beam cast with SF ratio $1 \%$ was $9.62 \%$ as compared with hybrid beam with SF ratio $0 \%$. As the web reinforcement increased from 0 to 0.004 and from 0 to 0.006 , the percentage increased in the ultimate load as $28.07 \%$ and $57.89 \%$, under monotonic loading as $26.14 \%$ and $59.09 \%$, under repeated loading.

Then, Strut and Tie model (STM) procedures were used to analyze the experimentally tested hybrid deep beams under monotonic loading of the present investigation. Comparison of experimental results was made with corresponding predicted values using the STM procedure presented of ACI 318R-14 Code and with other procedures

Keywords: High strength, Deep beam, Hybrid, Fibrous high strength concrete, Conventional concrete, Strut and Tie model.

\section{INTRODUCTION}

The deep beam could be defined as associate load on the face and the inversion face. The compression elements can

\footnotetext{
"Address correspondence to this author at the Civil Engineering Department, Al-Mustansiriayah University, Baghdad, Iraq, Tel: +6947712921362; E-mails: ans90ans@gmail.com; drc_sawsanakram@uomustansiriyah.edu.iq
} 
expand among the support and loads under ACI-Code 318R-14. The clear span and total depth ratio of less than four and the shear span to depth ratio of less than two [1]. There are many applications for reinforced concrete deep beams such as buildings, bridges, offshore structures and foundations. There are many structural elements which behave as a deep beam such as transfer beams, load-bearing walls and coupling beams in buildings, pile caps in foundations, plate elements in the folded plates and bunker walls [2]. Beams, in general, are classified as shallow beams, moderate deep beams, and deep beams according to their span to depth ratios. Beams whose depths are comparable to their spans may be described as deep beams. There is a distinct change in the behavior of deep beams and moderate deep beams because of the presence of local lateral normal forces in addition to usual bending moments and shear forces. This is not true for shallow beams. There is a gradual transition from shallow beam behavior to deep beam behavior. In construction, deep beams are widely used in water tanks, underground bunkers, silos, nuclear reactors, where walls act as vertical beams spanning between column supports. Sometimes pile caps are also designed as deep beams. Deep beams and moderate deep beams occur frequently in modern buildings such as departmental stores, hotels and theatres where it is desired to have the lower floor completely free of columns. In reinforced concrete hipped plate construction, the supporting diaphragms often behave as deep beams.

\section{AIM AND IDEA OF THE PRESENT STUDY}

The concept of hybrid deep beams in this work is different from the other works which use more than one type of concrete in cross section. In the precast work, the layers were cast vertically in longitudinal direction but not in crosssection. The aim is to strengthen shear spans which subjected to heavy shear forces (compression struts) lead to shear failure. Strengthen as done by adding steel fibers with different ratios to those spans increase their tensile strength. As the deep beams of the flexural members did not mention in the title 'the calculation of the shear force' because the main problem in this type of beam is the shear force and this was observed in the practical results. A flexural member whose span-to-depth ratio is too low to accurately apply the principles of sectional design through sectional properties and internal forces shear strength the maximum shearing stress a flexural member can support at a specific location as controlled by the combined effects of shear forces and bending moment.

\section{EXPERIMENTAL WORK}

A total of ten simply supported deep beams have been tested under two point loads to investigate the behavior of high strength hybrid reinforced concrete deep beams under monotonic and repeated loading. The tested beams have been designed to guarantee shear failure under monotonic loading according to ACI 318 R-14Code (STM). All beams had the same dimensions and flexural reinforcement. The amount of flexural reinforcement for all the tested beams was where is the flexural reinforcement ratio). The clear span between supports was $1230 \mathrm{~mm}$ which results in a ratio of clear span to generally depth of 3.5 which is less than 4.0 as recommended by the conditions of the ACI $318 \mathrm{M}-14$ Code for deep beam requirements. Table 1 shows tests results of mechanical properties for hardened concrete.

Table 1. Tests results of mechanical properties for hardened concrete.

\begin{tabular}{|c|c|c|c|c|c|c|c|c|c|}
\hline \multirow[t]{2}{*}{ Beam Designation } & \multirow[t]{2}{*}{ Type of Beam } & \multicolumn{2}{|c|}{$\begin{array}{c}\mathbf{f}^{\prime} \mathbf{c} \\
(\mathbf{M P a}) \\
\end{array}$} & \multicolumn{2}{|c|}{$\begin{array}{c}\mathrm{ft} \\
(\mathrm{MPa}) \\
\end{array}$} & \multicolumn{2}{|c|}{$\begin{array}{c}\mathbf{f r} \\
(\mathrm{MPa})\end{array}$} & \multicolumn{2}{|c|}{$\begin{array}{c}\text { Ec } \\
(\mathbf{G P a}) \\
\end{array}$} \\
\hline & & HSC & FHSC & HSC & FHSC & HSC & FHSC & HSC & FHSC \\
\hline $\begin{array}{l}\text { B -HS-M-FHSC } 1-\rho_{w} 4 \\
\text { B -HS-R-FHSC } 1-\rho_{w} 4 \\
\end{array}$ & $\begin{array}{l}\text { Non-Hybrid } \\
\text { (FHSC) }\end{array}$ & - & 56 & - & 7.12 & - & 11.5 & - & 81 \\
\hline $\begin{array}{l}\text { B -HS-M-Hy1- } \rho_{w} 4 \\
\text { B -HS-R-Hy1- } \rho_{w} 4\end{array}$ & Hybrid & 53.8 & 56 & 5.4 & 6.51 & 9.4 & 11.3 & 63 & 82.5 \\
\hline $\begin{array}{c}\text { B - HS-M-Hy1- } \rho_{w} 6 \\
\text { B -HS-R-Hy1- } \rho_{w} 6\end{array}$ & Hybrid & 53.8 & 56 & 5.4 & 6.51 & 9.4 & 11.3 & 63 & 82.5 \\
\hline $\begin{array}{l}\text { B -NC-M-Hy1- } \rho_{w} 4 \\
\text { B -NC-R-Hy1- } \rho_{w} 4\end{array}$ & $\begin{array}{l}\text { Hybrid } \\
\text { (NSC) }\end{array}$ & 27.33 & 29 & 3.54 & 4.75 & 3.5 & 5.5 & 23.5 & 24.7 \\
\hline $\begin{array}{l}\text { B -HS-M-HSC } 0-\rho_{w} 4 \\
\text { B -HS-R-HSC } 0-\rho_{w} 4\end{array}$ & $\begin{array}{l}\text { Non -Hybrid } \\
\text { (HSC) }\end{array}$ & 56.4 & - & 5.3 & - & 7.5 & - & 62.25 & - \\
\hline
\end{tabular}

The horizontal length of all longitudinal reinforcement $1460 \mathrm{~mm}$ and vertical length $250 \mathrm{~mm}$ to make $90^{\circ}$ hook to provide sufficient anchorage as shown in Fig. (1) 


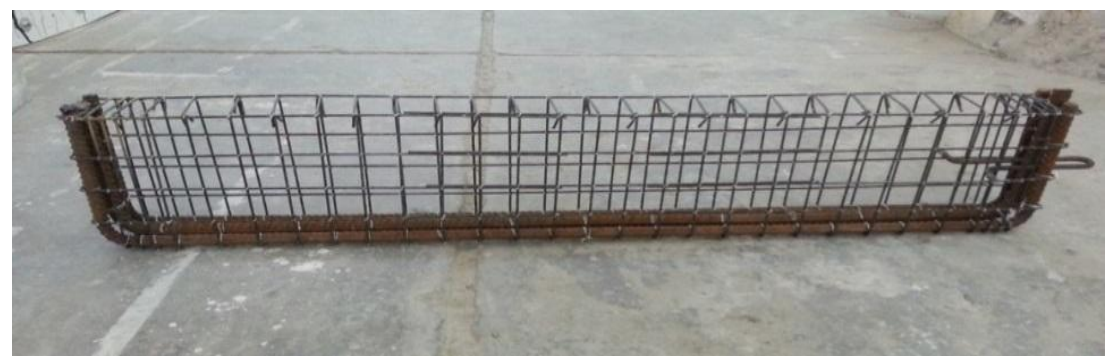

Fig. (1). Steel reinforcement cage used for deep beam.

\subsection{Molds}

The steel molds were designed for casting four hybrid deep beams for each batch as shown in Fig. (2). The inside dimensions for each mold were $1500 \mathrm{~mm}$ length,350 $\mathrm{mm}$ height and $150 \mathrm{~mm}$ width. The molds were designed to cast the beams vertically due to the difficulty of casting layers in a horizontal state. The front cover of the mold face of dimensions $1500 \mathrm{~mm} \times 350 \mathrm{~mm}$ consists of three plates. The lower plate was fixed to cast the first layer while the two other plates above were movable (doors) to cast the two other layers. Each door was closed before casting the layer of beam in it.

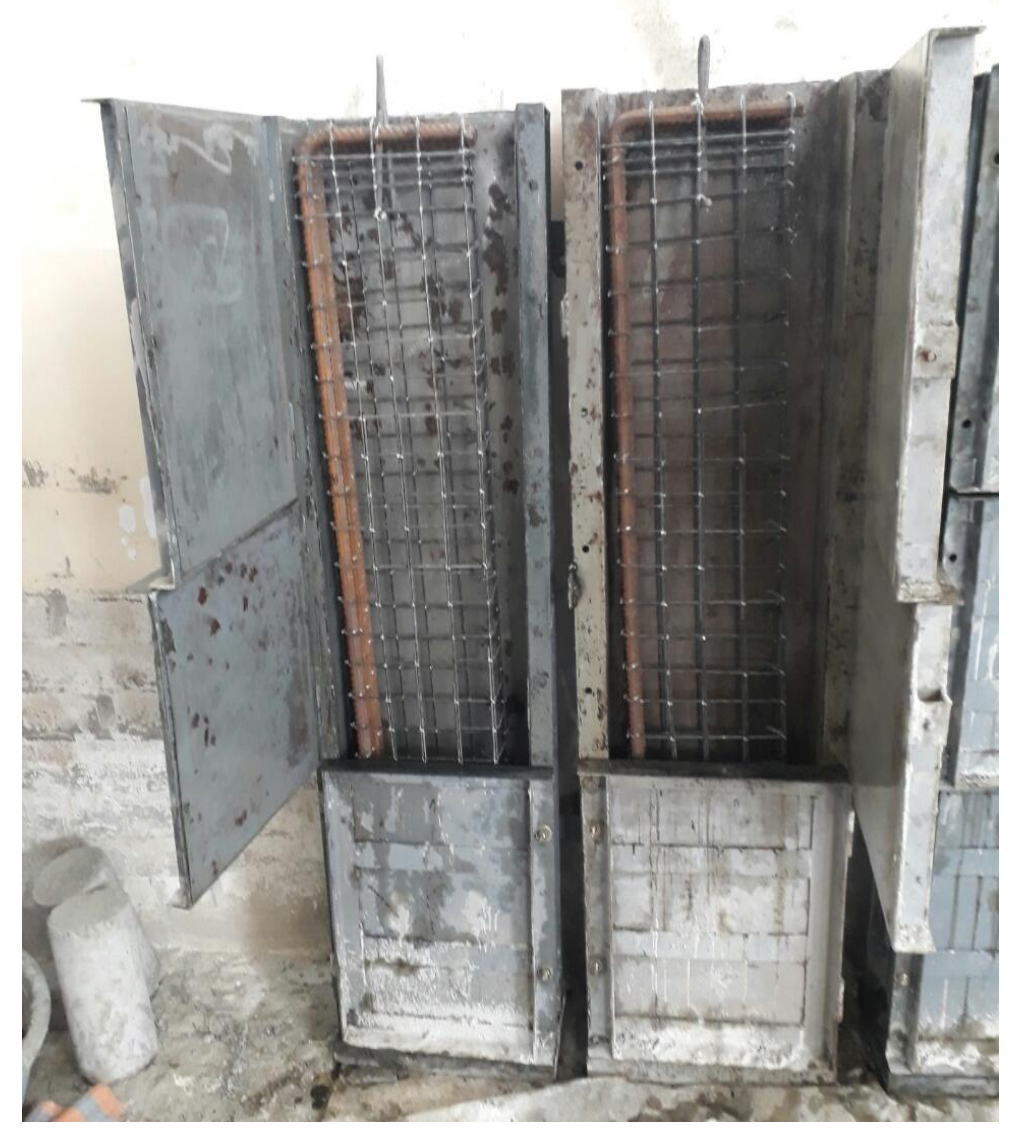

Fig. (2). Steel molds used for casting hybrid deep beams.

\subsection{Test Procedure}

In order to test the beam, the faces of the samples were coated in white color for observing cracks easily. The support and load point locations were positioned and thereafter, the points were mounted on the beams. The beams were categorized and the site of support point, loading point, and the digital gage places were noticeable on the beams to ease the accurate setup of testing machine. Thereafter, the beam was elevated by electrical crane and depressed on to supports. Beam specimens were located at the testing machine and checked so that the centerline supports, load arms 
and dial gages were fixed at their right and suitable positions. Loading process commences by application of two-point load from the testing machine to the higher face of beam.

All beam specimens have been loaded until failure for monotonic test and five cycles in repeated loading test. The beam samples have been loaded in increases of $10 \mathrm{kN}$, the rate of load increase was around $1.5 \mathrm{kN} / \mathrm{sec}$.

The locations and expansion of cracks for each cycle were noticeable on the surface of the beam. The failure happened, while the beam failed abruptly at simultaneity with the load index stopped in record or reoccurrence back and the deflection increased very quickly. The ultimate load has been noted, and the load has been removed to permit taking some photographs of the crack pattern and the mode of failure.

\section{EXPERIMENTAL RESULTS}

In monotonic loading, at low load levels, all the tested beams behaved in an elastic manner and the deflections at mid-span are small and proportional to the applied load. The first diagonal crack (web shear crack) appears at the diagonal region bounded by load and supports positions towards or parallel to the line joining the support with the load. The first flexure crack is observed in the lower part of the beam at the middle region between load positions. In repeated loading, at the first cycle, the behavior of deep beam specimens was similar to the behavior of beams under monotonic loading until the load reached the required load level. The cracks were opened during the first cycle as the required load level was reached, then closed at the unloading part of the cycle. Failure occurs by splitting the beam into two parts approximately along the line connecting the edge steel blocks at the support expect B-HS-M-Hy 1- $\rho_{\mathrm{w}} 6$ failed in flexural (crushing compression chord). Details of the tested beams and results obtained are shown in Table 2.

Table 2. Summary of test results for tested deep beams*.

\begin{tabular}{|c|c|c|c|c|c|c|c|c|}
\hline Beam Designation & Type of Beam & $\mathbf{f}^{\prime} \mathbf{c}$ & $\boldsymbol{\rho}_{\mathbf{w}} * *$ & $\begin{array}{c}\text { SF } \\
(\%)\end{array}$ & Type of Loading & $\begin{array}{l}\text { No. of } \\
\text { Cycles }\end{array}$ & Pu (kN) & $\begin{array}{l}\text { Mode of } \\
\text { Failure }\end{array}$ \\
\hline B -HS-M-FHSC $1-\rho_{w} 4$ & $\begin{array}{l}\text { Non- } \\
\text { Hybrid } \\
\text { (FHSC) }\end{array}$ & 60 & $0.004 * * *(\mathrm{Min})$ & 1 & Monotonic & - & 810 & Diagonal Shear Failure \\
\hline B -HS-R-FHSC $1-\rho_{w} 4$ & $\begin{array}{l}\text { Non- } \\
\text { Hybrid } \\
\text { (FHSC) }\end{array}$ & 60 & $\begin{array}{l}0.004 \\
\text { (Min) }\end{array}$ & 1 & $\begin{array}{c}\text { Repeated ( } 75 \% \text { of Ultimate Load } \\
\text { for Last Beam) }\end{array}$ & 5 & 640 & Diagonal Shear Failure \\
\hline B -HS-M-Hy1- $\rho_{w} 4$ & Hybrid & 60 & 0.004 (Min) & 1 & Monotonic & - & 730 & Diagonal Shear Failure \\
\hline B -HS-R-Hy1- $\rho_{w} 4$ & Hybrid & 60 & 0.004 (Min) & 1 & $\begin{array}{c}\text { Repeated ( } 75 \% \text { of Ultimate Load } \\
\text { for Last Beam) }\end{array}$ & 5 & 555 & Diagonal Shear Failure \\
\hline B - HS-M-Hy $1-\rho_{w} 6$ & Hybrid & 60 & $\begin{array}{c}0.006 \\
(>\operatorname{Min})\end{array}$ & 1 & Monotonic & - & 900 & Diagonal Shear Failure \\
\hline B -HS-R-Hy1- $\rho_{w} 6$ & Hybrid & 60 & $\begin{array}{c}0.006 \\
(>\operatorname{Min})\end{array}$ & 1 & $\begin{array}{c}\text { Repeated ( } 75 \% \text { of Ultimate Load } \\
\text { for Last Beam) }\end{array}$ & 5 & 700 & Shear-Flexural Failure \\
\hline B -NC-M-Hy1- $\rho_{w} 4$ & Hybrid & 30 & $\begin{array}{l}0.004 \\
(\mathrm{Min})\end{array}$ & 1 & Monotonic & - & 370 & Diagonal Shear Failure \\
\hline B -NC-R-Hy1- $\rho_{w} 4$ & Hybrid & 30 & $\begin{array}{l}0.004 \\
(\mathrm{Min})\end{array}$ & 1 & $\begin{array}{c}\text { Repeated ( } 75 \% \text { of Ultimate Load } \\
\text { for Last Beam) }\end{array}$ & 5 & 280 & Diagonal Shear Failure \\
\hline B -HS-M-HSC $0-\rho_{w} 4$ & $\begin{array}{l}\text { Non-Hybrid } \\
\text { (HSC) }\end{array}$ & 60 & 0.004 (Min) & 0 & Monotonic & - & 610 & Diagonal Shear Failure \\
\hline B -HS-R-HSC $0-\rho_{w} 4$ & $\begin{array}{l}\text { Non-Hybrid } \\
\text { (HSC) }\end{array}$ & 60 & 0.004 (Min) & 0 & $\begin{array}{l}\text { Repeated ( } 75 \% \text { of Ultimate Load } \\
\text { for Last Beam) }\end{array}$ & 5 & 470 & Diagonal Shear Failure \\
\hline
\end{tabular}

*All beams have the same $(\mathrm{a} / \mathrm{h})$ ratio $=1.14$.

Figs. (3a-j) shows mode of failure and the crack pattern of the tested deep beams after testing. 


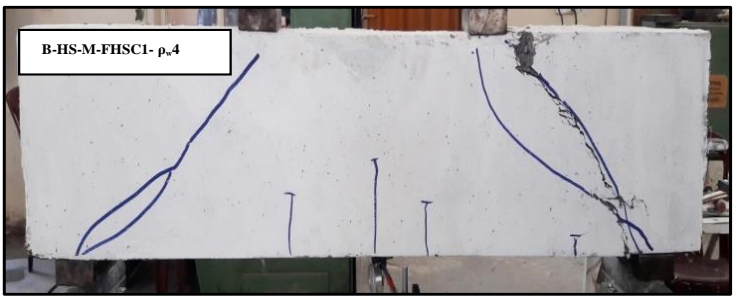

a. B-HS-M-FHSC1- $\rho_{\mathrm{w}} 4$

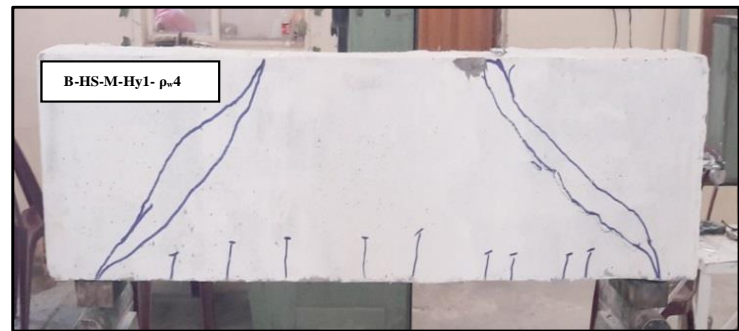

c. B-HS-M-Hy1- $\rho_{\mathrm{w}} 4$

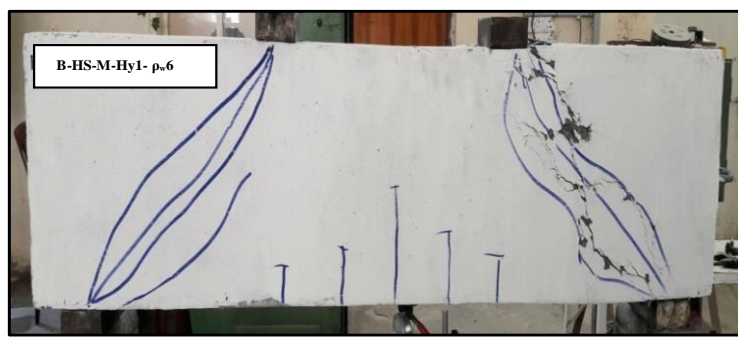

e. B-HS-M-Hy1- $\rho_{w} 6$

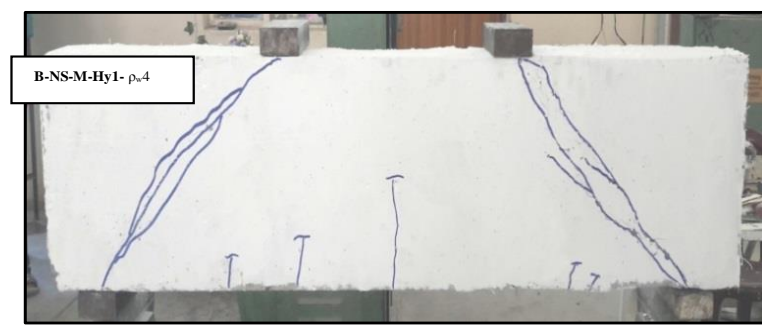

g. B-NS-M-Hy1- $\rho_{w} 4$

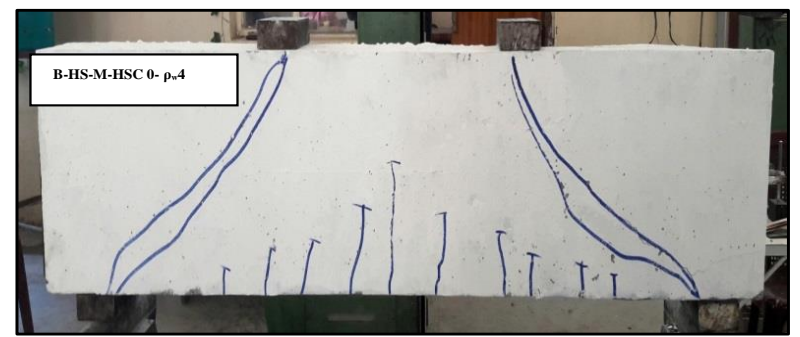

i. B-HS-M-HSC 0- $\rho_{\mathrm{w}} 4$

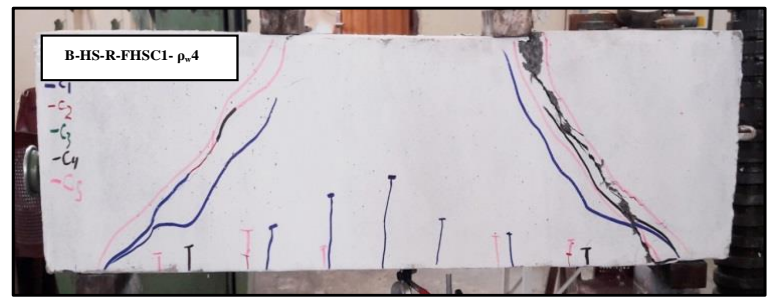

b. B-HS-R-FHSC1- $\rho_{\mathrm{w}} 4$

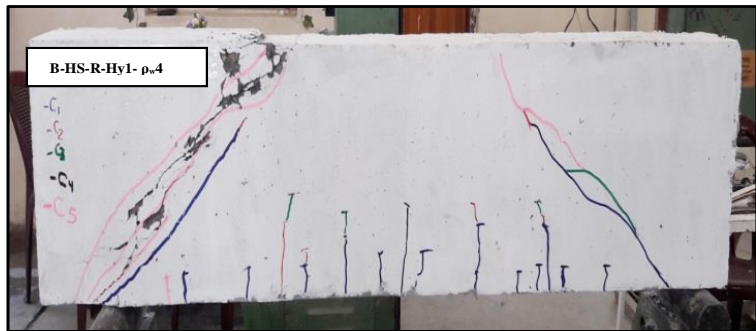

d. B-HS-R-Hy1- $\rho_{w} 4$

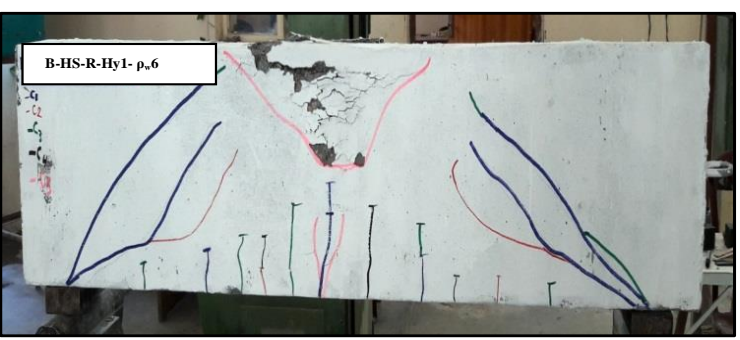

f. B-HS-R-Hy1- $\rho_{w} 6$

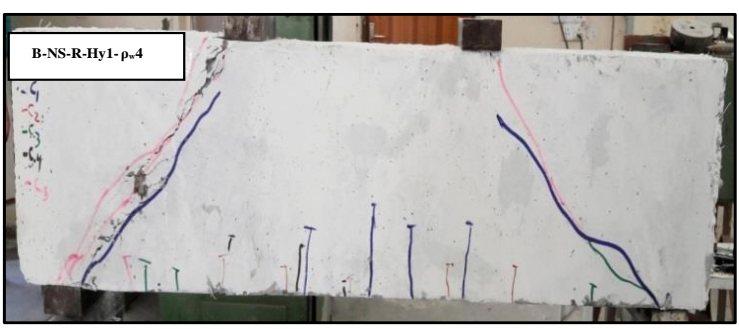

h. B-NS-R-Hy1- $\rho_{w} 4$

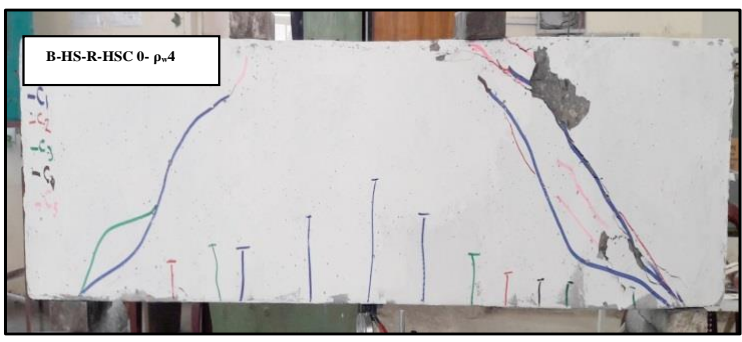

j. B-HS-R-HSC $0-\rho_{\mathrm{w}} 4$

Fig. (3). Mode of failure and the crack pattern of the tested deep beams.

\subsection{Effect of Many Parameters on the Ultimate Load of Tested Beams}

Type of loading in deep beams monotonic and repeated with load level $75 \%$ from monotonic. Table 3 explains the effect type of loading on the ultimate load. 


\subsubsection{Effect Type of Loading}

Table 3. Effect of loading type for all tested deep beam.

\begin{tabular}{|c|c|c|c|c|c|c|c|c|}
\hline Beam Designation & Type of Beam & $\mathbf{f}^{\prime} \mathbf{c}$ & $\boldsymbol{\rho}_{\mathrm{w}}$ & $\begin{array}{l}\text { SF } \\
(\%)\end{array}$ & Type of Loading & $\begin{array}{l}\text { No. of } \\
\text { Cycle }\end{array}$ & $\left|\begin{array}{c}\mathbf{P u} \\
(\mathbf{k N})\end{array}\right|$ & $\begin{array}{c}\% \\
\text { Percentage } \\
\text { Decrease }\end{array}$ \\
\hline B -HS-M-FHSC $1-\rho_{w} 4$ & $\begin{array}{l}\text { Non- } \\
\text { Hybrid } \\
\text { (FHSC) }\end{array}$ & 60 & 0.004 & 1 & $\begin{array}{l}\text { Monotonic } \\
\text { (Control) }\end{array}$ & - & 810 & \multirow{2}{*}{20.98} \\
\hline B -HS-R-FHSC 1- $\rho_{w} 4$ & $\begin{array}{l}\text { Non- } \\
\text { Hybrid } \\
\text { (FHSC) }\end{array}$ & 60 & .0040 & 1 & Repeated( $75 \%$ of Control Beam Load) & 5 & 640 & \\
\hline B -HS-M-Hy1- $\rho_{w} 4$ & Hybrid & 60 & 0.004 & 1 & $\begin{array}{c}\text { Monotonic } \\
\text { (Control) }\end{array}$ & - & 730 & \multirow[t]{2}{*}{23.97} \\
\hline B -HS-R-Hy $1 \%-\rho_{w} 4$ & Hybrid & 60 & 0.004 & 1 & Repeated(75\% of Control Beam Load) & 5 & 555 & \\
\hline B - HS-M-Hy $1-\rho_{w} 6$ & Hybrid & 60 & 0.006 & 1 & $\begin{array}{l}\text { Monotonic } \\
\text { (Control) }\end{array}$ & - & 900 & \multirow{2}{*}{22.22} \\
\hline B -HS-R-Hy1- $\rho_{w} 6$ & Hybrid & 60 & 0.006 & 1 & Repeated $(75 \%$ of Control Beam Load & 5 & 700 & \\
\hline B -NC-M-Hy1- $\rho_{w} 4$ & Hybrid & 30 & 0.004 & 1 & $\begin{array}{l}\text { Monotonic } \\
\text { (Control) }\end{array}$ & - & 370 & \multirow[t]{2}{*}{24.32} \\
\hline B -NC-R-Hy1- $\rho_{w} 4$ & Hybrid & 30 & 0.004 & 1 & Repeated(75\% of Control Beam Load) & 5 & 280 & \\
\hline B -HS-M-HSC $0-\rho_{w} 4$ & $\begin{array}{l}\text { Non- } \\
\text { Hybrid } \\
\text { (HSC) }\end{array}$ & 60 & 0.004 & 0 & $\begin{array}{l}\text { Monotonic } \\
\text { (Control) }\end{array}$ & - & 610 & \multirow{2}{*}{22.95} \\
\hline B -HS-R-HSC $0-\rho_{w} 4$ & $\begin{array}{l}\text { Non- } \\
\text { Hybrid } \\
\text { (HSC) }\end{array}$ & 60 & 0.004 & 0 & Repeated( $75 \%$ of Control Beam Load) & 5 & 470 & \\
\hline
\end{tabular}

From the observation of Table $\mathbf{3}$, the following notes can be noticed:

1. The decreased percentages in the ultimate load according to the repeated loading for non-hybrid deep beams of HSC and FHSC are convergent which are $22.95 \%$ and $20.98 \%$, respectively.

2. The decreased percentages in the ultimate load according to the repeated loading of hybrid deep beams which have web reinforcement $(0.004$ and 0.006$)$ as variable are convergent which are $23.97 \%$ and $22.22 \%$, respectively.

3. The decreased percentages in the ultimate load according to the repeated loading of hybrid deep beams with compressive strength concrete (high and normal) as variable are convergent which are $23.97 \%$ and $24.32 \%$, respectively.

4. The average value of the decreased percentages of beams subjected to monotonic and $75 \%$ of the repeated loading is $22.88 \%$.

\subsection{Effect Compressive Strength of Concrete}

\subsubsection{Under Monotonic Loading}

Fig. (4) and Table 4 shows the effect of the compressive strength of concrete on the ultimate loads for deep beams which were tested under monotonic loading. About $30 \mathrm{MPa}$ and $60 \mathrm{MPa}$.

Table 4. Effect of the compressive strength of concrete on ultimate load of beams under monotonic loading.

\begin{tabular}{|c|c|c|c|c|c|}
\hline Beam Designation & $\begin{array}{c}\text { Type of } \\
\text { Beam }\end{array}$ & $\begin{array}{c}\text { SF } \\
\mathbf{( \% )}\end{array}$ & $\boldsymbol{\rho}_{\mathbf{w}}$ & $\begin{array}{c}\text { Ultimate Load (Pu) } \\
(\mathbf{k N})\end{array}$ & \% Increase Ultimate Load * \\
\hline B-NS-M-Hy1- $\rho_{w} 4$ & Hybrid(NS) & 1 & 0.004 & 370 & - \\
\hline B-HS-M-Hy1- $\rho_{w} 4$ & Hybrid(HS) & 1 & 0.004 & 730 & 97.3 \\
\hline
\end{tabular}

*The percentage increase is measured with respect to beam B-NS-M-Hy1 $\rho_{w} 4$.

The results in Table 4 show the increase in ultimate load in hybrid deep beams tested under monotonic load beam 
B-HS-M-Hy1- $\rho_{w} 4$ is $97.3 \%$ as compared with beam B-NC-M-Hy1- $\rho_{w} 4$. It can be observed that as the compressive strength increases, the capacity increased which is an expected result.

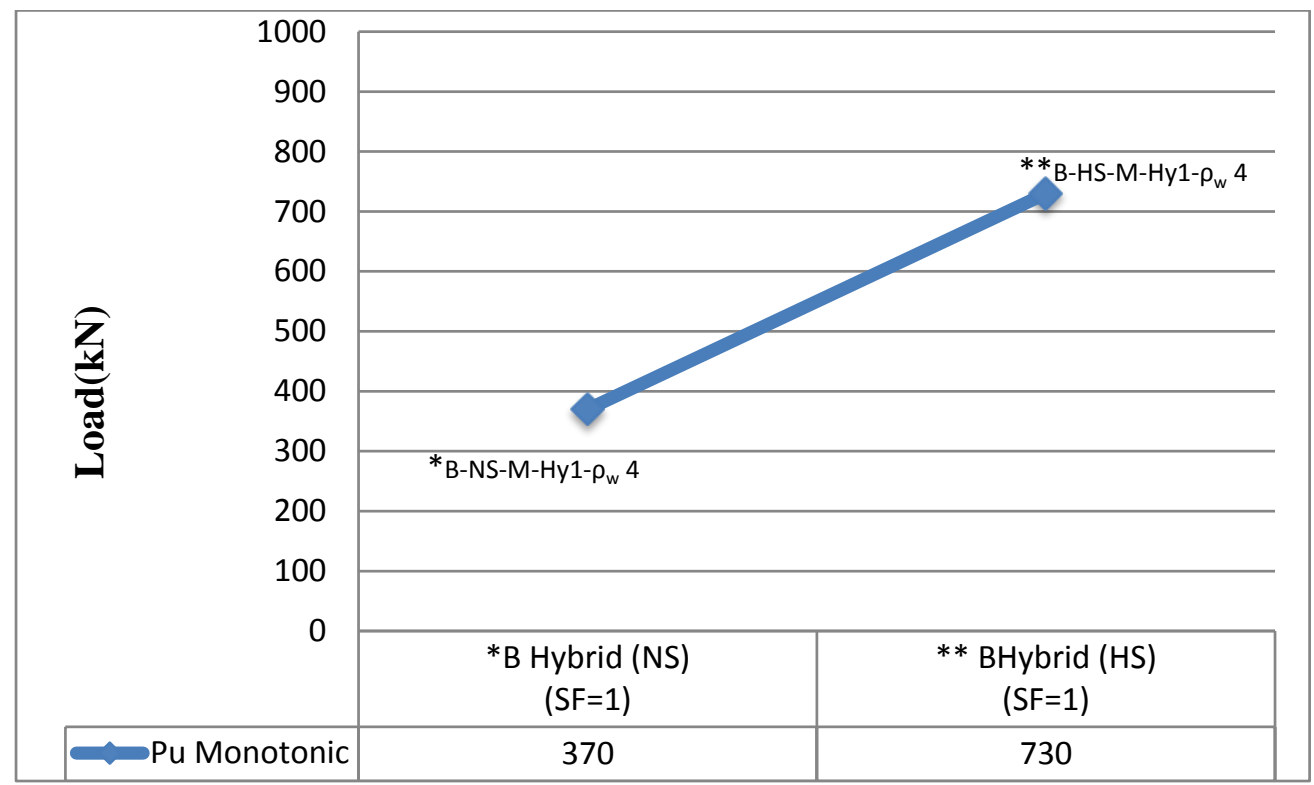

Fig. (4). Effect compressive strength of concrete on ultimate load of beams under monotonic loading.

\subsubsection{Under Repeated Loading}

Fig. (5) and Table 5 shows the effect of strength of concrete (as $30 \mathrm{MPa}$ and $60 \mathrm{MPa}$ ) on an ultimate load of hybrid deep beam tested under repeated loading level of $75 \%$ of control monotonic loading.

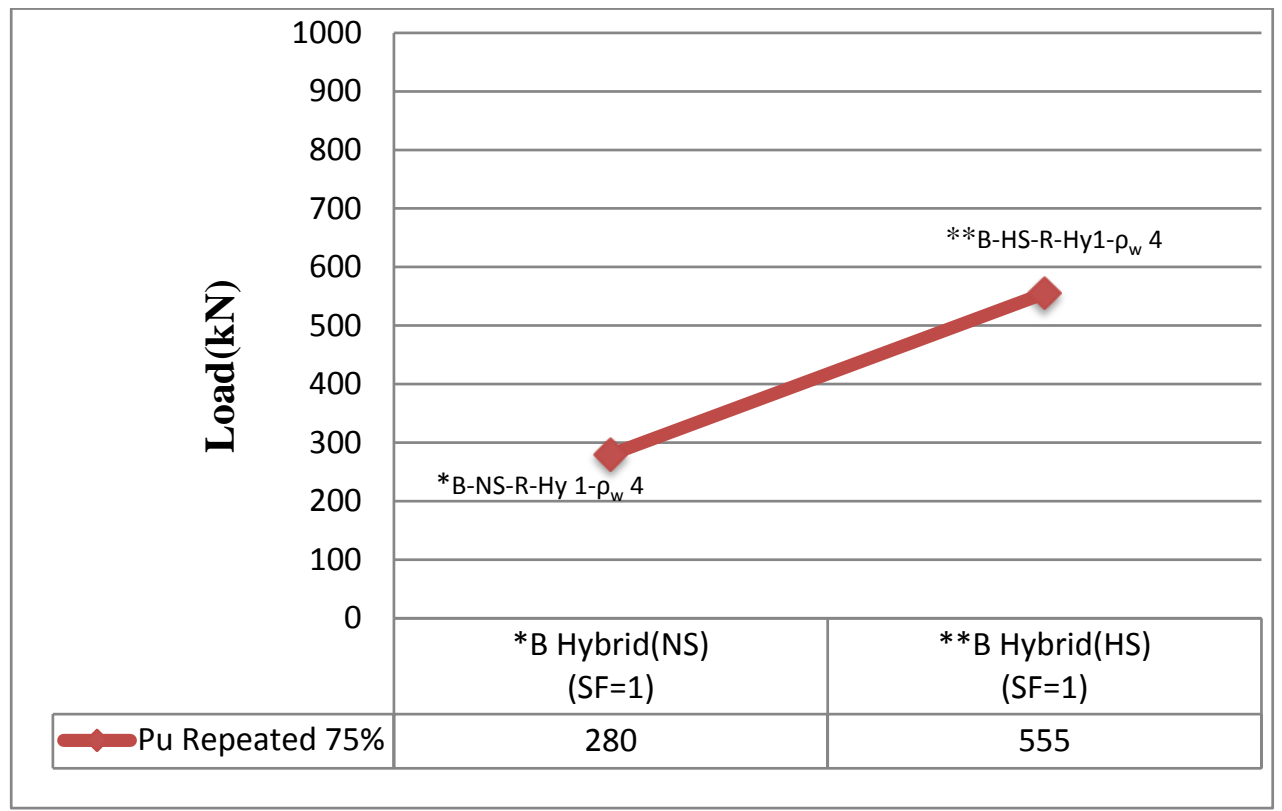

Fig. (5). Effect of compressive strength of concrete on ultimate load of beams under repeated loading. 
Table 5. Effect type of beam on ultimate load under monotonic loading.

\begin{tabular}{|c|c|c|c|c|c|}
\hline Beam Designation & $\begin{array}{c}\text { Type of } \\
\text { Beam }\end{array}$ & $\begin{array}{c}\text { SF } \\
(\%)\end{array}$ & $\boldsymbol{\rho}_{\mathbf{w}}$ & $\begin{array}{c}\text { Ultimate Load (Pu) } \\
(\mathbf{k N})\end{array}$ & \%Increase Ultimate Load* \\
\hline B-NS-R-Hy1- $\rho_{w} 4$ & Hybrid (NC) & 1 & 0.004 & 280 & - \\
\hline B-HS-R-Hy1- $\rho_{w} 4$ & $\begin{array}{c}\text { Hybrid } \\
\text { (HS) }\end{array}$ & 1 & 0.004 & 555 & 98.21 \\
\hline
\end{tabular}

*The percentage of increase is measured with respect to beam B-NS-R-Hy1- $\rho_{w} 4$.

From the results in Table $\mathbf{5}$, it can be seen that hybrid beams tested under repeated loading with higher compressive strength have a higher ultimate load. The percentage increases ultimate load, hybrid beam B-HS-R-Hy1- $\rho_{w} 4$. From Tables $\mathbf{4}$ and $\mathbf{5}$., it can be seen that in both types of loading (repeated and monotonic), the ultimate load is doubled as the compressive strength increased from $28.17 \mathrm{MPa}$ to $55 \mathrm{MPa}$.

\subsection{Effect Type of Beam}

\subsubsection{Under Monotonic Loading}

Effects of the variable type of beam on the ultimate load for deep beams tested under monotonic load in this research are shown in Fig. (6) and Table 6. Beam B-HS-M-HSC 0- $\rho_{w} 4$ was cast using HSC, beam B-HS-M-FHSC1- $\rho_{w}$ 4 was cast using FHSC and beam B-HS-M-Hy1- $\rho_{w} 4$ was cast hybrid (HSC at mid span and FHSC at sides).

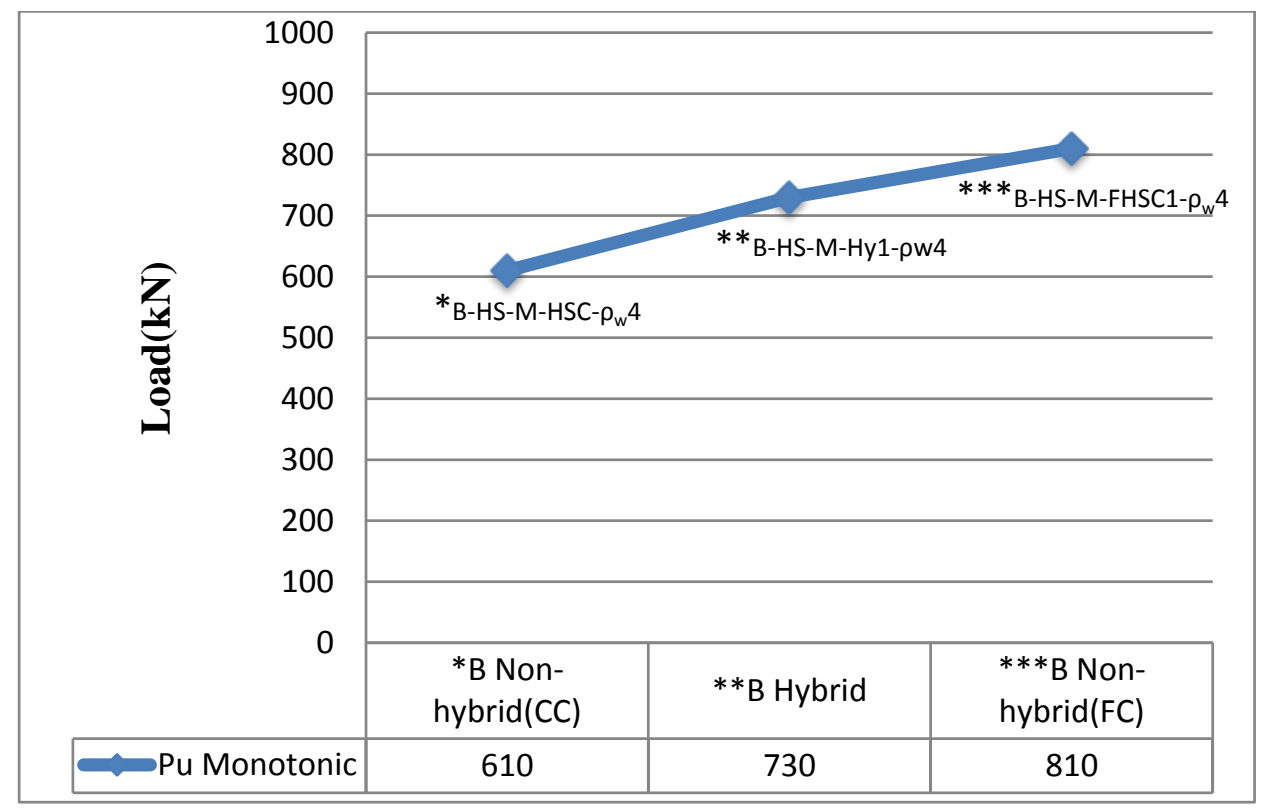

Fig. (6). Effect type of beam on ultimate load under monotonic loading.

Table 6. Effect type of beam on ultimate load under monotonic loading.

\begin{tabular}{|c|c|c|c|c|c|}
\hline Beam Designation & $\begin{array}{c}\text { Type of } \\
\text { Beam }\end{array}$ & $\begin{array}{c}\text { SF } \\
\mathbf{( \% )}\end{array}$ & $\boldsymbol{\rho}_{\mathbf{w}}$ & $\begin{array}{c}\text { Ultimate Load (Pu) } \\
(\mathbf{k N})\end{array}$ & \% Increase Ultimate Load * \\
\hline B-HS-M-HSC $0-\rho_{w} 4$ & Non -Hybrid (HSC) & 0 & 0.004 & 610 & - \\
\hline B-HS-M-Hy1- $\rho_{w} 4$ & Hybrid & 1 & 0.004 & 730 & 19.67 \\
\hline B-HS-M-FHSC $1-\rho_{w} 4$ & Non-Hybrid (FHSC) & 1 & 0.004 & 810 & $* * 32.79$ \\
\hline
\end{tabular}

*The percentage of increase is measured with respect to beam B-HS-M-HSC $0-\rho_{w} 4 . * *$ The percentage of increase of a load of beam B-HS-M-FHSC $1-\rho_{w} 4$ is 10.96 with respect to beam B-HS-M-Hy1- $\rho_{w} 4$.

The results presented in Table 6, show that the increase in ultimate load for beam B-HS-M-FHSC1- $\rho_{w} 4$ which cast using FHSC and beam B-HS-M-Hy1- $\rho_{w} 4$ is about $32.79 \%$ and $19.67 \%$, respectively, with respect to beam B-HS-MHSC $0-\rho_{w} 4$ which cast with HSC. From this result, it is observed that the extension ratio of SF (1\%) to beam B-HS-MHyl $-\rho_{w} 4$ in shear spans only leads to improve the amount of resistance by a significant ratio of $19.67 \%$, while when the 
same proportion of SF was extended through the length of the beam B-HS-M-FHSC1- $\rho_{w} 4$, the percent of increase is also significant $32.79 \%$ but a bit higher than the hybrid beam with SF only at shear spans $10.96 \%$.

\subsubsection{Under Repeated Loading}

Fig. (7) and Table 7 shows the effect of the beam type on ultimate load for deep beams tested under repeated loading by $75 \%$ of the ultimate monotonic loading of its control beams.

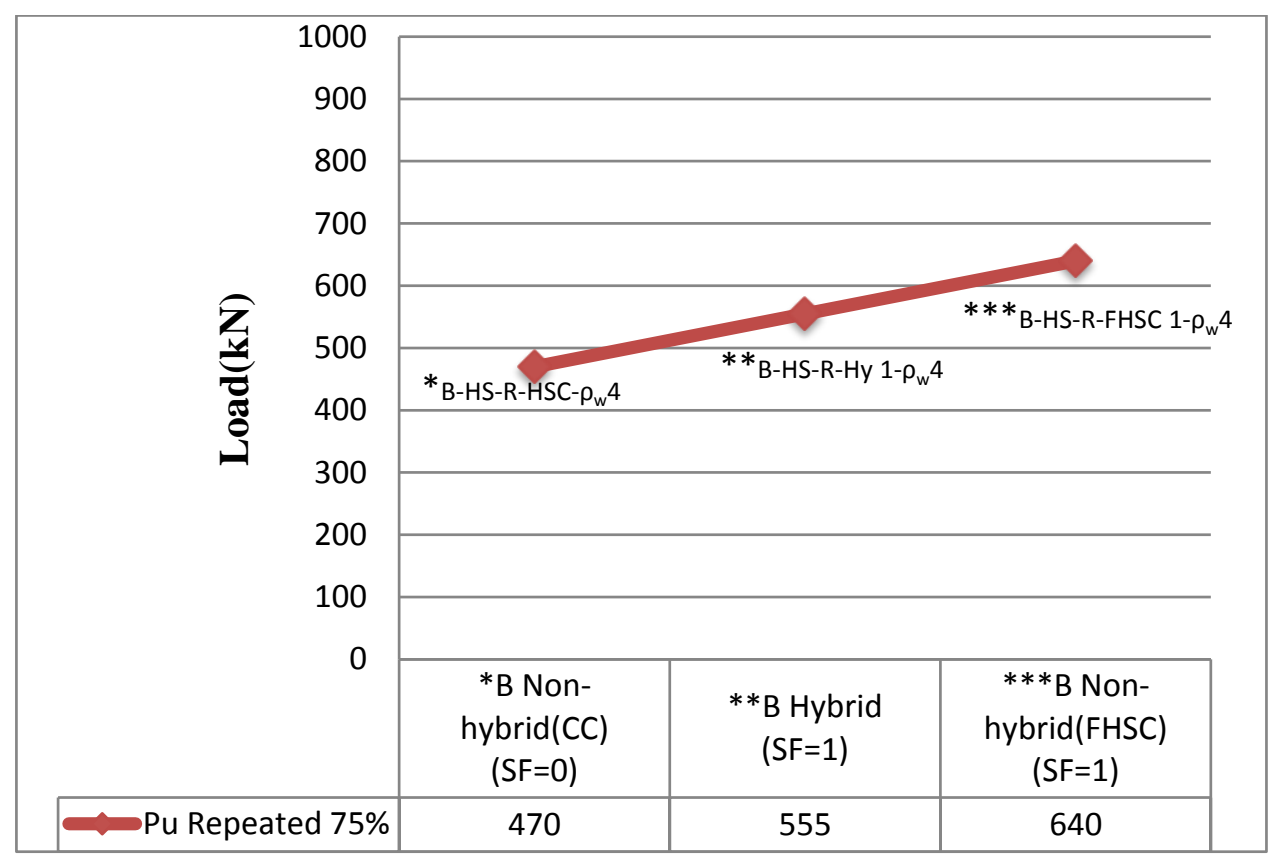

Fig. (7). Effect type of beam on ultimate load under repeated loading.

Table 7. Effect type of beam on ultimate load under repeated loading.

\begin{tabular}{|c|c|c|c|c|c|}
\hline Beam Designation & $\begin{array}{c}\text { Type of } \\
\text { Beam }\end{array}$ & $\begin{array}{c}\text { SF } \\
(\mathbf{\%})\end{array}$ & ${ }_{w} \boldsymbol{\rho}$ & $\begin{array}{c}\text { Ultimate Load (Pu) } \\
(\mathbf{k N})\end{array}$ & $\begin{array}{c}\text { \% Increase Ultimate } \\
\text { Load * }\end{array}$ \\
\hline B-HS-R-HSC $0-\rho_{w} 4$ & Non-Hybrid (HSC) & 0 & 0.004 & 470 & - \\
\hline B-HS-R-Hy1- $\rho_{w} 4$ & Hybrid & 1 & 0.004 & 555 & 18.09 \\
\hline B-HS-R-FHSC $1-\rho_{w} 4$ & Non-Hybrid (FHSC) & 1 & 0.004 & 640 & $* * 36.17$ \\
\hline
\end{tabular}

*The increased percentage is measured with respect to beam B-HS-R-HSC $0 \%-\rho_{w} 4 .{ }^{* *}$ The percentage increase of load of beam B-HS-R-FHSC $1 \%-$ $\rho_{w} 4$ is 15.32 with respect to beam B-HS-R-Hy1\%- $\rho_{w} 4$.

From the results in Table 7, it can be seen that the hybrid deep beam B-HS-R-Hy1- $\rho_{w} 4$ fails in load higher than non-hybrid deep beam cast with HSC by $18.09 \%$, while deep beam B-HS-R-FHSC $1-\rho_{w} 4$ which was cast from FHSC with SF ratio of $1 \%$ fails in load higher than the two beams B-HS-R-HSC $0-\rho_{w} 4$ and B-HS-R-Hy1- $\rho_{w} 4$ by $36.17 \%$ and $15.32 \%$, respectively. It can be concluded that the ratio of SF in the region of pure bending in beams subjected to the repeated loading level of $75 \%$ of monotonic ultimate load of like beams are more considerable when beams subjected to repeated loading than in monotonic loading.

\subsection{Effect of Web Reinforcement Ratio $\left(\rho_{w}\right)$}

Three arrangements of web reinforcement were considered $(0,0.004,0.006)$. The ratio 0.004 represents minimum web reinforcement (minimum horizontal 0.0025 and minimum vertical 0.0025 ).

\subsection{1. under Monotonic Loading}

Effect of amount of web reinforcement is calculated under the constant ratio of SF and a/h ratio for two types of loading monotonic and repeated of $75 \%$ control ultimate load. The results of the variable $\rho_{w}$ are shown in Fig. (8) and Table 8. 


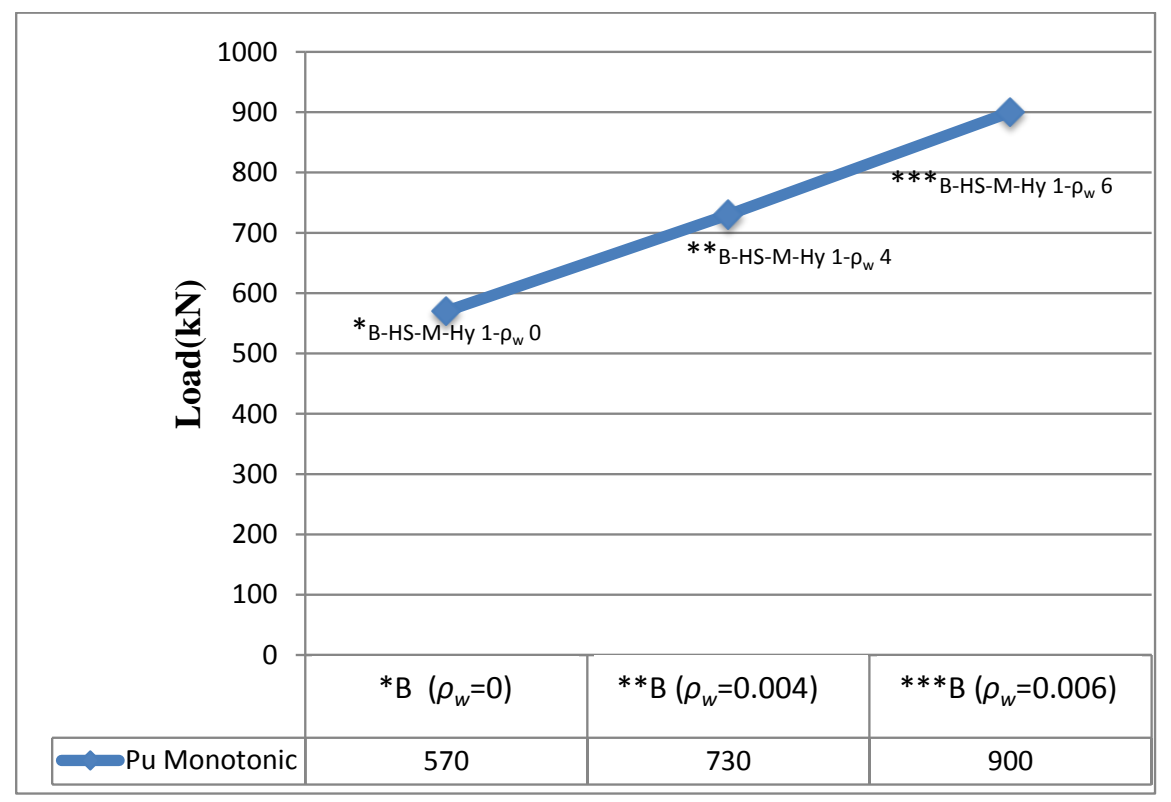

Fig. (8). Effect of $\rho_{\mathrm{w}}$ on ultimate load of beams under monotonic loading.

Table 8. Effect of $\rho_{w}$ on ultimate load of beams under monotonic loading.

\begin{tabular}{|c|c|c|c|c|c|}
\hline Beam Designation & $\begin{array}{c}\text { Type of } \\
\text { Beam }\end{array}$ & $\begin{array}{c}\text { SF } \\
\mathbf{( \% )}\end{array}$ & $\boldsymbol{\rho}_{\mathbf{w}}$ & $\begin{array}{c}\text { Ultimate Load (Pu) } \\
(\mathbf{k N})\end{array}$ & $\begin{array}{c}\text { \% Increase Ultimate } \\
\text { Load * }\end{array}$ \\
\hline B-HS-M-Hy1- $\rho_{w} 0$ & Hybrid & 1 & 0.0 & 570 & - \\
\hline B-HS-M-Hy1- $\rho_{w 4}$ & Hybrid & 1 & 0.004 & 730 & 28.07 \\
\hline B- HS-M-Hy1- $\rho_{w} 6$ & Hybrid & 1 & 0.006 & 900 & $* * 57.89$ \\
\hline
\end{tabular}

* The percentage of increase is measured with respect to beam B-HS-M-Hy $1 \%-\rho_{w}=0$.

\subsubsection{Under Repeated Loading}

The effect of an ultimate load for hybrid deep beams under repeated loading of level $75 \%$ of control monotonic loading is shown in Fig. (9) and Table 9.

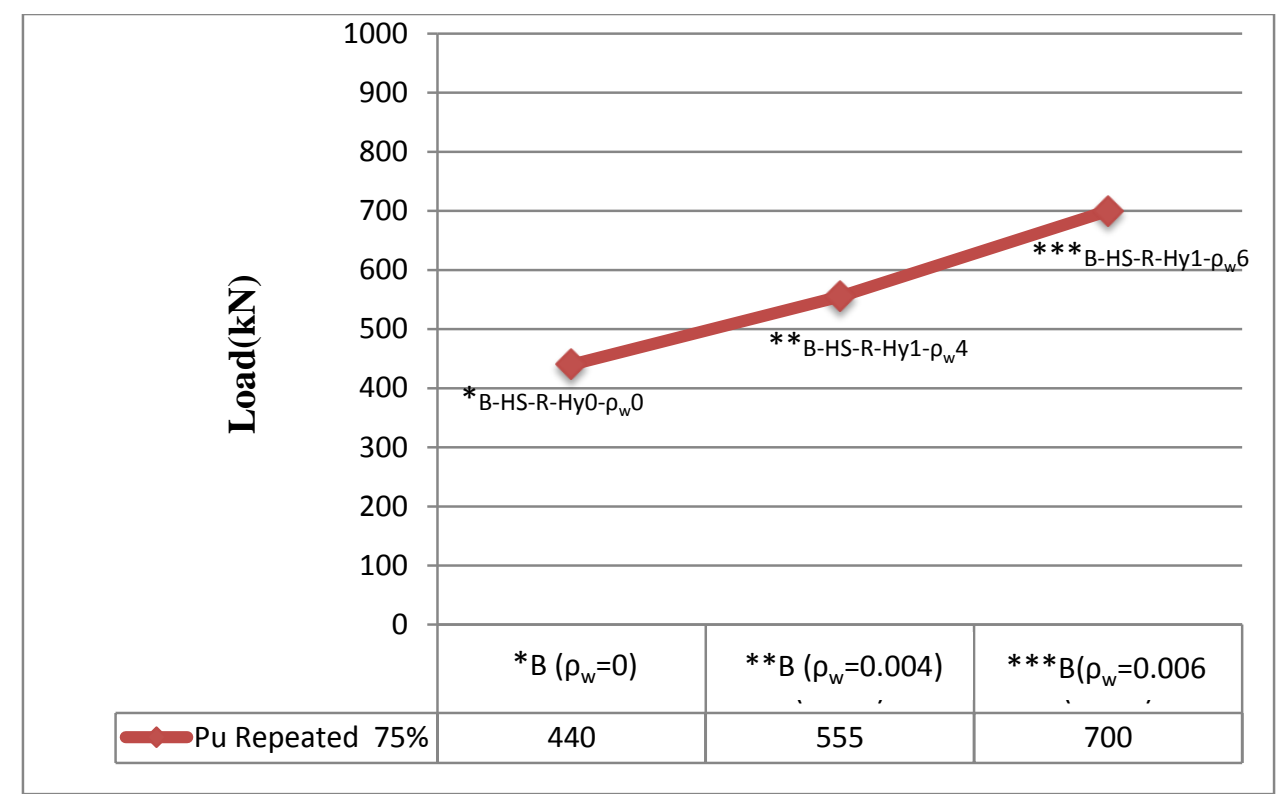

Fig. (9). Effect of $\rho_{w}$ on ultimate load of beams under repeated loading. 
Table 9. Effect of $\rho_{\mathrm{w}}$ on ultimate load of beams under repeated loading.

\begin{tabular}{|c|c|c|c|c|c|}
\hline Beam Designation & $\begin{array}{c}\text { Type of } \\
\text { Beam }\end{array}$ & $\begin{array}{c}\text { SF } \\
\mathbf{( \% )}\end{array}$ & $\mathbf{\rho}_{\mathbf{w}}$ & $\begin{array}{c}\text { Ultimate Load (Pu) } \\
(\mathbf{k N})\end{array}$ & $\begin{array}{c}\text { \% Increase Ultimate } \\
\text { Load * }\end{array}$ \\
\hline B-HS-R-Hy1- $\rho_{w} 0$ & Hybrid & 1 & 0.0 & 440 & - \\
\hline B-HS-R-Hy1- $\rho_{w} 4$ & Hybrid & 1 & 0.004 & 555 & 26.14 \\
\hline B-HS-R-Hy1- $\rho_{w} 6$ & Hybrid & 1 & 0.006 & 700 & $* * 59.09$ \\
\hline
\end{tabular}

*The percentage of increase is measured with respect to beam B-HS-R-Hy $1 \%-\rho_{w}=0$. ** the increased percentages of load of the beam B-HS-R-Hy1$\rho_{w} 6$ is $26.13 \%$ with respect B-HS-R-Hy1- $\rho_{w} 4$.

It can be seen that there is an increase in the value of ultimate load value of $26.14 \%$ as $p_{w}$ increases from ( 0 to $0.004)$ while there is an increase in ultimate load value of $59.1 \%$ as the $p_{w}$ increased from (0 to 0.006$)$. It can be concluded that presence of web reinforcement contributes to enhance shear capacities of hybrid deep beams with significant effected under monotonic and repeated loading. Also, the increase in web reinforcement ratio from 0.004 to 0.006 increases the capacity by $26.13 \%$.

\subsection{Load-Deflection Response}

\subsubsection{Effect Compressive Strength of Concrete}

Fig. (10) shows the effect of the compressive strength of concrete of hybrid deep beams with SF $1 \%$ on loaddeflection response under monotonic loading. Two types of strength were used. Hybrid beam B-HSC-M-Hy1- $\rho_{w} 4$. with normal strength ( $\mathrm{f}^{\prime} \mathrm{c}=28.17 \mathrm{Mpa}$ ) has the smaller deflection values at each stage of loading as compared to beam B -HSM-Hy1- $\rho_{w} 4$ that has high strength (f'c=55Mpa).

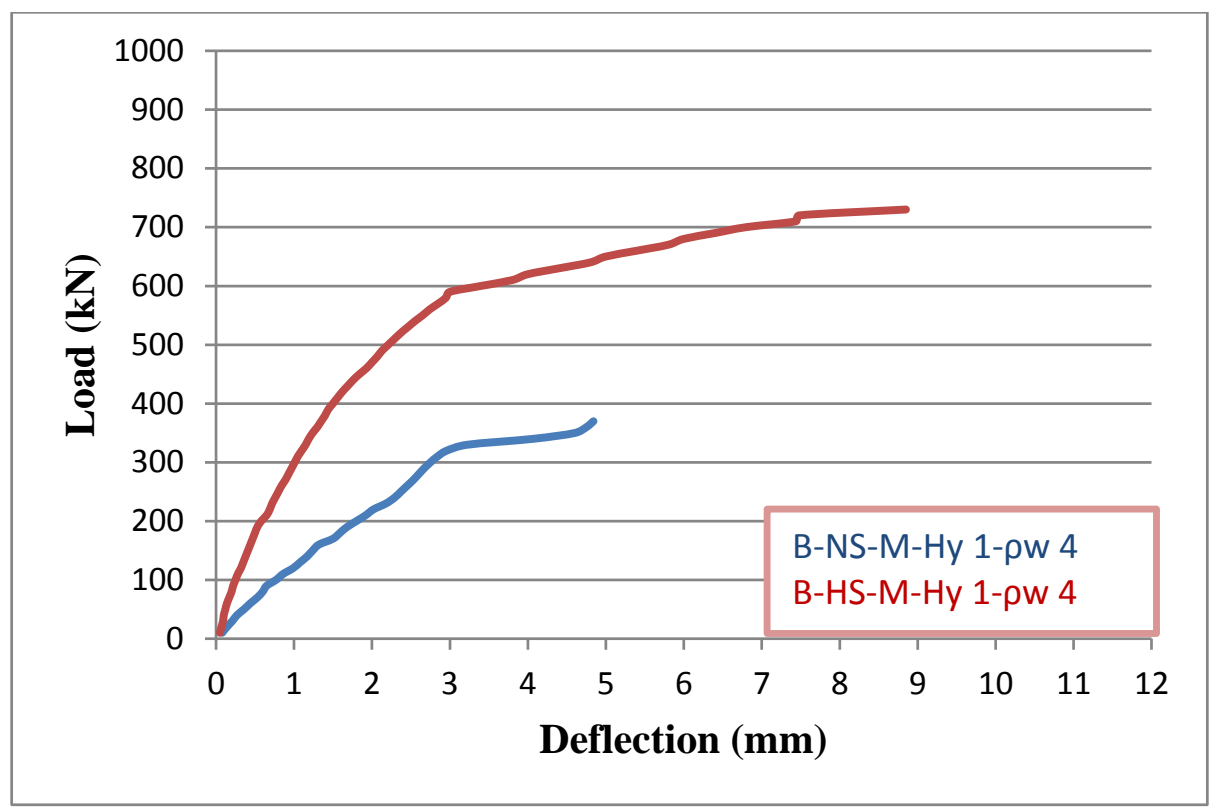

Fig. (10). Load-deflection relationship for hybrid beams with different strength of concrete under monotonic loading.

\subsubsection{Effect Type of Beam}

Fig. (11) shows the difference between load-deflection relationship of non-hybrid (HSC) beam B-HS-M-HSC 0$\rho_{\mathrm{w}} 4$, beam B-HS-M-Hy1- $\rho_{w} 4$ (hybrid beam with SF ratio 1\% in shear spans) and non-hybrid (FHSC) beam B-HS-MFHSC $-\rho_{\mathrm{w}} 4$ with SF ratio of $1 \%$ along entire beam length under monotonic loading. 


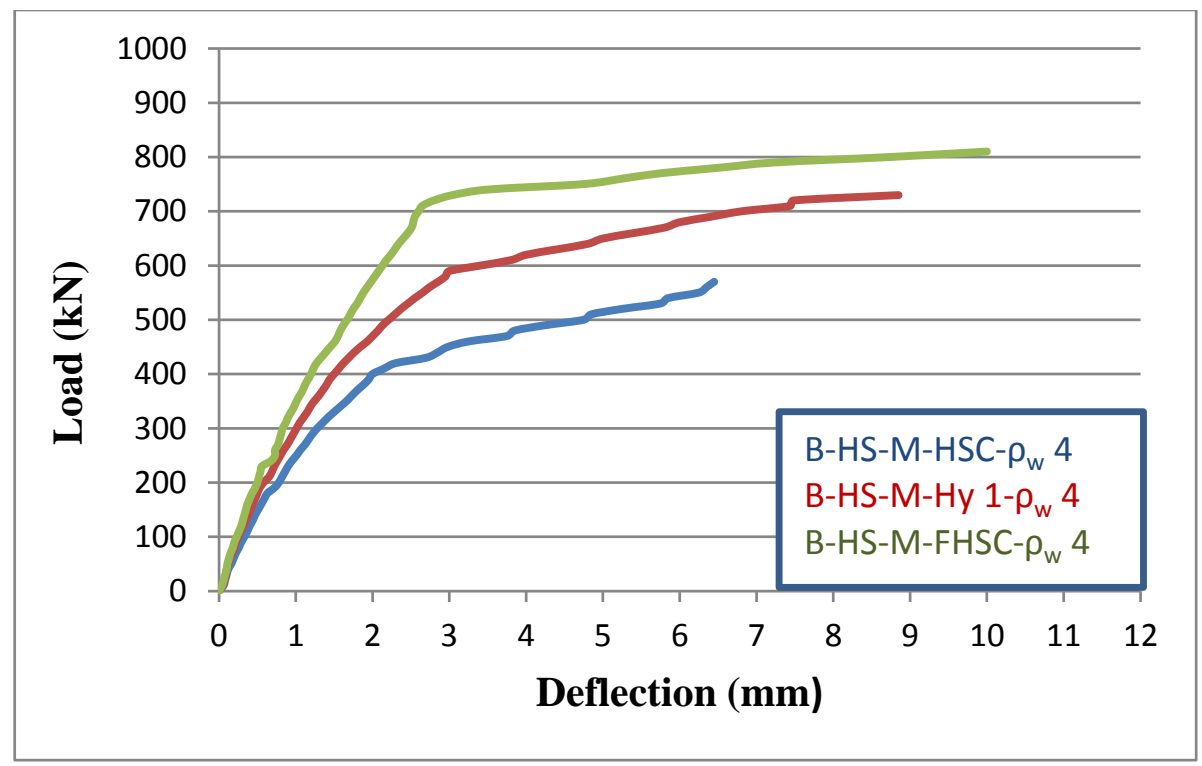

Fig. (11). Load-deflection relationship for different type of beam under monotonic loading.

\subsubsection{Effect of Web Reinforcement Ratio}

Increasing web reinforcement with different amounts contributed in improving the performance of beams. Fig. (12) shows the effect of $\rho_{w}$ on load- deflection response for hybrid beams which are tested under monotonic loading.

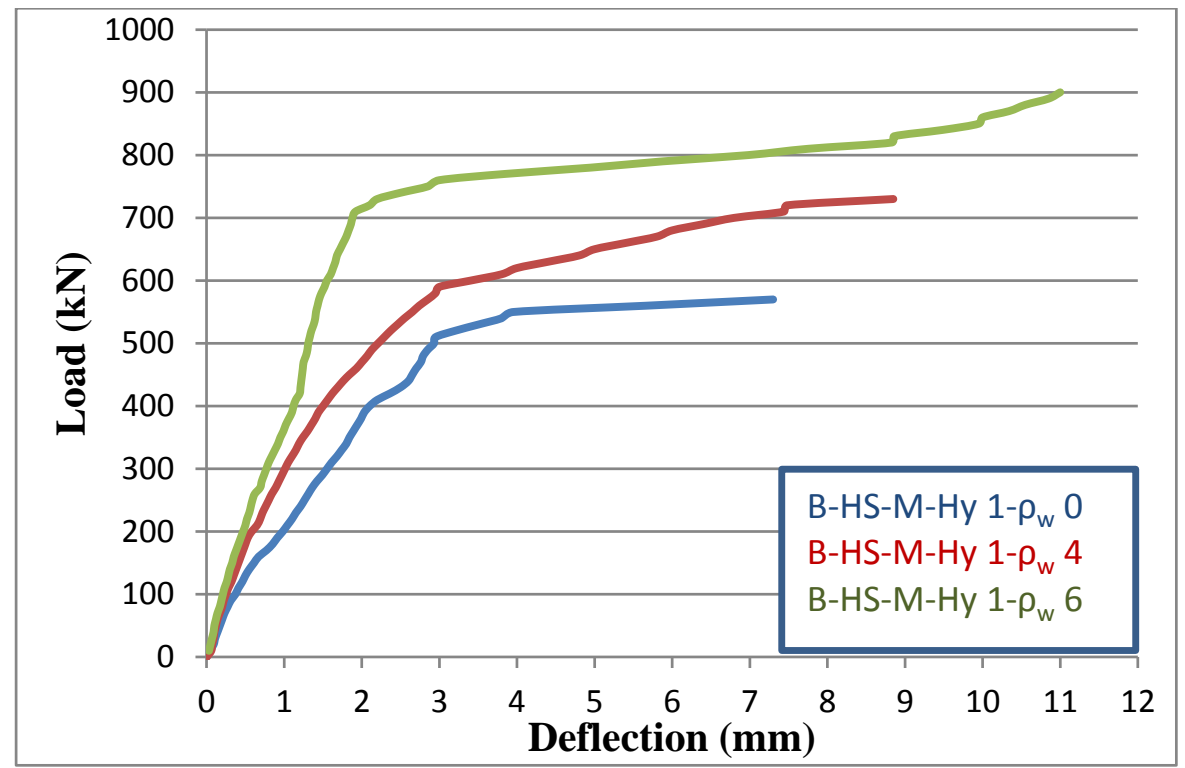

Fig. (12). Load-deflection relationship for hybrid beams with different $\rho_{w}$ ratios under monotonic loading.

\section{ANALYTICAL WORK}

Based on the lower-bound theorem, the STM is applied, in which the stress applied to the elements of the STM should not exceed their maximum capacities, and the truss model shall be in equilibrium. When these conditions are met, the truss will exhibit the deformation capacity required by the lower-bound theorem to redistribute the internal stresses and form the arch action [3]. Also, this chapter involves the establishment of the analytical methods that depend on STM techniques for predicting an ultimate load of hybrid HSC deep beams to obtain reasonable and accurate methods of analysis of this type of beams in comparison with available experimental data were analyzed using the following analytical methods: 
1. STM according to ACI 318R-14Code [1].

2. Modified STM proposed by Zhang and Tan in March 2007.

3. Modified STM proposed by Zhang and Tan in November 2007.

\subsection{Related Work}

1. Remodeling buildings often imply a modification of the mechanical behavior of the structural system, which may include the application of concentrated loads to beams that before have only been subjected to distributed loads. In the case of reinforced concrete beams, the new condition causes the beam to support a concentrated load in the cracked condition determined by the distributed loads that had been acting in the past. If the concentrated load is applied at or near the mid-span of the beam, consequently, the shear demand reaches its maximum where the shear capacity is low. At and near the mid-span, in fact, the cracks in the tension zone are vertical like the stirrups. Therefore, the truss mechanism provides the shear capacity with a nil contribution, since both the struts and ties are vertical. Fiberreinforced polymer composites allow these beams to increase their shear strength, up to guaranteeing adequate safety. A method for analyzing the mechanical behavior of beams with vertical cracks, strengthened with FRP reinforcement, subjected to concentrated loads. The method defines the direction of the fibers that the reinforcement has to be composed of and computes the shear strength of the beam [4].

2. A multiscale analytical model that predicts the lifetime of concrete members with externally bonded FRP reinforcement. The lifetime is dictated by the de-bonding of external reinforcement, which takes place within the concrete cover, where micro-cracks (initial flaws) propagate due to the shear stresses that the bond subjects the concrete cover too. The lifetime is estimated from the propagation of such cracks until a critical crack length is eventually reached, which causes the external FRP reinforcement to lose the bond (delayed de-bonding). The model provides a closed form-solution for the life-through estimation of the external reinforcement, which consists of the interaction between bond shear stresses and lifetime (maximum bond shear stress versus delayed time, i.e. the ultimate domain). Crack growth is modeled at the mesoscale, where the velocity of the cracks depends on the model stress intensity factor, but not on the microstructure. The model assumes that the carbonation process has reduced the plasticity and cohesion of the concrete cover to zero; thus, the predictions are slightly conservative (lower bound model). Some experimental results on real scale beams are presented to corroborate the theoretical findings. A practical application of the model shows that delayed de-bonding significantly reduces the service life of concrete members with externally bonded FRP reinforcement [5].

3. The investigation relates to flexural concrete members strengthened by means of external reinforcement bonded adhesively onto the surface, in particular, by fiber-reinforced polymeric strips, sheets, or laminates. Investigation specifically devoted to external reinforcement being already in tension under a dead load or a low fraction of live load. The concrete cover exhibits initial flaws, which were unimportant when a member was not externally reinforced, but that may give rise to slow crack propagation up to delayed de-bonding when the member is externally reinforced. This paper presents a model for predicting the delayed de-bonding. The common de-bonding models, including code provisions, focus mainly on the structural and material scales, and thus ignore delayed failure. On the contrary, this new model focusses on the mesoscale, which considers the velocity of crack growth that leads to de-bonding. While on the nanoscale and microscale, the crack velocity depends on the microstructure. On the mesoscale, the crack velocity depends on the interfacial bond shear stresses and crack length. This dependence can be synthetized by the ratio between the two models. The model describes the delayed de-bonding in terms of interaction between bond shear stress and time (ultimate domain maximum bond shear stress versus delayed time) [6].

\subsection{Elements of STM}

STM in deep beams is represented by a structural truss. Each type of the elements in an STM serves a unique purpose but must act in conformity to describe accurately the behavior of a structure.

STM consists of the following members and parts:

\subsubsection{Struts}

Struts are the compression members in the STM. Compression struts fulfill two functions in the STM [1].

1. They serve as the compression zone of the truss which resists moment (prismatic strut). 
2. They serve as the diagonal struts which transfer shear to the supports (bottle-shaped strut). Fig. (13) illustrates bottle-shaped, prismatic, and idealized prismatic struts found in a typical STM [10].

$$
\begin{aligned}
& \text { Bottle-Shape } \\
& \text { Strut }
\end{aligned}
$$

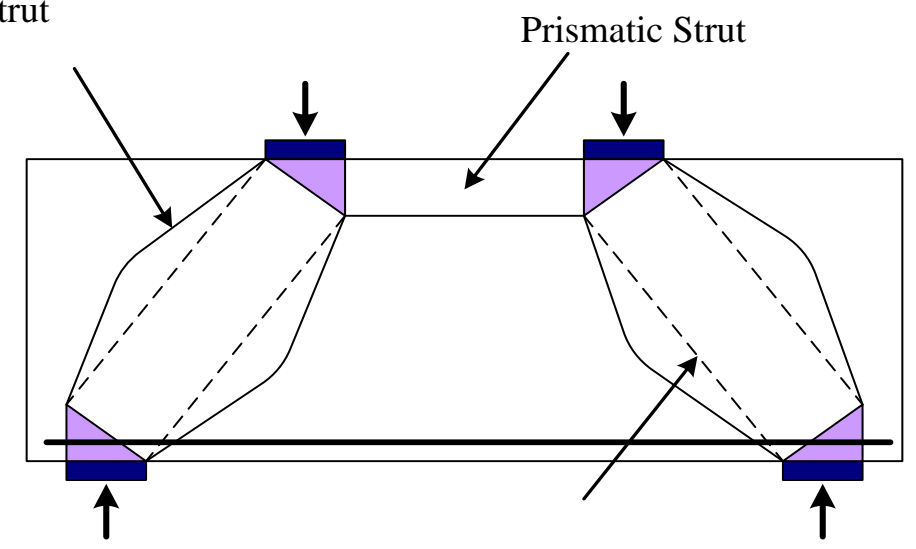

Idealized Prismatic

Strut

Fig. (13). Strut and Tie Model containing prismatic and bottle-shaped struts.

\subsubsection{Ties}

Ties are the tension members in the STM, which can be expressed as a reinforcing steel bar. The reinforcement must be dispersed so that its centroid conformities with the tie location. Details like distribution spacing, bar and anchorage are factors that justify the most consideration when placing the reinforcement and selecting [7].

\subsubsection{Nodes}

Nodes are locations at which struts and ties converge, it the connections of the STM. For example, the nodal zone where 2 struts and a tie meet is mentioned to as a CCT node (C mentions for compression and $\mathrm{T}$ mentions for tension) $[7]$.

\section{ANALYTICAL RESULTS}

\subsection{Capacity of the Tested Beams Using the STM}

In the present work, the ultimate load for eight simply supported deep beams which were tested under monotonic loading is calculated according to ACI 318 R-14 Code [1]. The comparison between test results and the expected values of the ultimate load is shown in Table 10. From Table 11, it can be noticed that the STM mentioned in ACI 318R-14 Code underestimates the load capacity of deep beams for some beams and overestimates capacities for the other beams. The mean value $\left(\mathrm{X}^{\prime}\right)$ for the ratio of analytical/test results of ultimate loads $\left(\mathrm{P}_{\mathbf{A n}} / \mathrm{P}_{\text {Exp }}\right)$ is 0.94 where $\mathrm{P}_{\mathrm{An}}$ refers to ultimate loads obtained using analytical methods and $\mathrm{P}_{\mathbf{E x p}}$ refers to ultimate loads obtained from experimental test, the standard deviation (SD) is 0.14 and the coefficient of variation (CV) is 0.15 .

\begin{tabular}{|c|c|c|c|c|c|c|}
\hline \multirow[t]{2}{*}{ Beam Designation } & \multirow[t]{2}{*}{$\boldsymbol{\rho}_{\mathrm{w}}$} & \multirow[t]{2}{*}{ Type of Beam } & \multirow{2}{*}{$\begin{array}{l}\text { SF } \\
(\%)\end{array}$} & \multicolumn{2}{|c|}{$\begin{array}{c}\text { Ultimate Load }\left(2 V_{n}\right) \\
(k N)\end{array}$} & \multirow[t]{2}{*}{$\% \mathbf{P}_{\text {An }} / \mathbf{P}_{\text {Exp. }}$} \\
\hline & & & & STM ACI 318R-14 Code & Experimental Value & \\
\hline B-HS-M-FHSC $1-\rho_{w} 4$ & \begin{tabular}{|c|}
0.004 \\
(Min.)
\end{tabular} & $\begin{array}{l}\text { Non-Hybrid } \\
\text { (FHSC) }\end{array}$ & 1 & 694 & 810 & 0.86 \\
\hline B-HS-M-Hy $1-\rho_{w} 4$ & 0.004 & Hybrid & 1 & 694 & 730 & 0.95 \\
\hline B- HS-M-Hy1- $\rho_{w} 6$ & \begin{tabular}{|c|}
0.006 \\
$(>$ Min. $)$
\end{tabular} & Hybrid & 1 & 694 & 900 & 0.77 \\
\hline B-NS-M-Hy1- $\rho_{w} 4$ & 0.004 & Hybrid & 1 & 360 & 370 & 0.97 \\
\hline
\end{tabular}

Table 10. Comparison between experimental ultimate loads and those calculated using STM of ACI 318R-14Code [1]. 
(Table 1[) contd.....

\begin{tabular}{|c|c|c|c|c|c|c|}
\hline \multirow[t]{2}{*}{ Beam Designation } & \multirow[t]{2}{*}{$\boldsymbol{\rho}_{\mathrm{w}}$} & \multirow[t]{2}{*}{ Type of Beam } & \multirow{2}{*}{$\begin{array}{l}\text { SF } \\
(\%)\end{array}$} & \multicolumn{2}{|c|}{$\begin{array}{c}\text { Ultimate Load }\left(2 V_{n}\right) \\
(k N)\end{array}$} & \multirow[t]{2}{*}{$\% \mathbf{P}_{\text {An }} / \mathbf{P}_{\text {Exp. }}$} \\
\hline & & & & STM ACI 318R-14 Code & Experimental Value & \\
\hline B-HS-M-HSC $0-\rho_{w} 4$ & 0.004 & $\begin{array}{c}\text { Non-Hybrid } \\
\text { (HSC) }\end{array}$ & 0 & 699 & 610 & 1.14 \\
\hline
\end{tabular}

$\mathrm{X}^{\prime}=0.94$ SD. $=0.14 \mathrm{CV} .=0.15$

\subsection{Modified of STM Theory}

Zhang and Tan in March (2007) [8], submitted a modified STM for calculation of shear strength of reinforced concrete deep beams based on a previous investigation reported by Tan and Cheng [9]. From the structural analysis for simply supported reinforced concrete beams dependent to symmetric two point loads, it is well known that the ultimate load $(\mathrm{P})$ is equal to twice the shear force at the support as per Eq. (1).

$$
\mathrm{P}=2 V_{n}
$$

The expression for calculation shear strength $\mathrm{V}_{\mathrm{n}}$ according to Zhang and Tan [5], is as follows in Eq. (2)

$$
V_{n}=\frac{1}{\frac{4 \sin \theta_{s} \cos \theta_{s}}{A_{c} f_{t}}+\frac{\sin \theta_{s}}{A_{s t r} f_{C}^{\prime}}}
$$

where;

$V_{n}$ : shear strength of deep beams (N).

$A_{c}$ : is the beam effective cross- sectional area $\left(\mathrm{mm}^{2}\right)$, equals to $\mathrm{b}_{\mathrm{w}} \mathrm{d}_{\mathrm{c}}$.

$\mathrm{d}_{\mathrm{c}}$ : effective beam depth $(\mathrm{mm})$.

$A_{s t r}:$ cross-sectional area of the concrete diagonal strut $\left(\mathrm{mm}^{2}\right)$, equal to $\mathrm{W}_{\mathrm{s}} \mathrm{b}_{\mathrm{w}}$

$\mathrm{W}_{\mathrm{s}}$ : effective width of the inclined strut $(\mathrm{mm})$.

$\mathrm{b}_{\mathrm{w}}$ : width of deep beam $(\mathrm{mm})$.

$f_{i}$ : combined tensile strength of reinforcement and concrete (MPa).

$O_{s}$ : angle between the axis of the strut and the horizontal axis of the member.

It can be noted that the expression is the composite tensile strength included contributions from concrete and reinforcement (web and main bars), in Eq. (3)

$$
f_{t}=f_{c t}+f_{s t}
$$

where; $f_{c t}$ : represents the contribution of concrete tensile strength. $f_{s t}$ : represents the contribution of steel reinforcement which consists of two parts, $f_{s w}$ from the web reinforcement and $f_{s s}$ from the longitudinal reinforcement as explain in Eq (4).

$$
f_{s t}=f_{s w}+f_{s s}
$$

Zhang and Tan submitted that the presence of web reinforcement in the strut restricts the inclined cracks from readily increase to every end of the strut. Eq. (5) shows the tensile contribution of web reinforcement at the interface of the nodal zone.

$$
f_{s w}=\frac{A_{s w} f_{y w} \sin \left(\theta_{s}+\theta_{w}\right)}{A_{c} / \sin \theta_{s}}
$$

For conformity cases of vertical and horizontal web reinforcement, Eq. (6) is reduced to:

$$
f_{s w}=\frac{A_{s v} f_{y v} \sin 2 \theta_{s}}{2 A_{c}}+\frac{A_{s h} f_{y h} \sin ^{2} \theta_{s}}{A_{c}}
$$


Where:

$A_{s v}$ : total areas of vertical web reinforcement within the shear span $\left(\mathrm{mm}^{2}\right)$.

$A_{s h}$ : total areas of horizontal web reinforcement within the shear span $\left(\mathrm{mm}^{2}\right)$.

$f_{s h}$ : tensile yield strength of vertical web reinforcement (MPa).

$f_{y h}$ : tensile yield strength of horizontal web reinforcement (MPa).

$\theta_{s}$ : angle between the axis of the strut and the horizontal axis of the member.

$\theta_{w}$ : angle between the web reinforcement and the horizontal axis of beams at the intersection of the reinforcement and the diagonal strut.

The expression $f_{s s}$ refers to the contribution of bottom longitudinal steel, it can be obtained according to the following Eq. (7):

$$
f_{S S}=\frac{4 A_{s} f_{y} \sin \theta_{S}}{A_{c} / \sin \theta_{s}}
$$

Where:

$A_{s}$ : total areas of bottom longitudinal main reinforcement $\left(\mathrm{mm}^{2}\right)$.

$f_{y}$ : tensile yield strength of main reinforcement (MPa).

Table 11 summarized the strength of the deep beams of the present investigation.

Table 11. Comparison between experimental ultimate loads and those calculated using modified STM theory by N. Zhang and K.H. Tan.

\begin{tabular}{|c|c|c|c|c|c|c|}
\hline \multirow[t]{2}{*}{ Beam Designation } & \multirow[t]{2}{*}{$\boldsymbol{\rho}_{w}$} & \multirow[t]{2}{*}{ Type of Beam } & \multirow{2}{*}{$\begin{array}{l}\text { SF } \\
(\%)\end{array}$} & \multicolumn{2}{|c|}{$\begin{array}{c}\text { Ultimate Load }\left(2 V_{n}\right) \\
(k N)\end{array}$} & \multirow{2}{*}{$\begin{array}{c}\% \\
\mathbf{P}_{\mathrm{An}} / \mathbf{P}_{\mathrm{ExI}}\end{array}$} \\
\hline & & & & Modified STM by Zhang and Tan & Experimental Value & \\
\hline B-HS-M-FHSC $1-\rho_{w} 4$ & 0.004 & $\begin{array}{c}\text { Non-Hybrid } \\
\text { (FHSC) }\end{array}$ & 1 & 833 & 810 & 1.03 \\
\hline B-HS-M-Hy $1-\rho_{w} 4$ & 0.004 & Hybrid & 1 & 823 & 730 & 1.13 \\
\hline B- HS-M-Hy 1- $\rho_{w} 6$ & 0.006 & Hybrid & 1 & 851 & 900 & 0.95 \\
\hline B-NC-M-Hy $1-\rho_{w} 4$ & 0.004 & Hybrid & 1 & 656 & 370 & 1.77 \\
\hline B-HS-M-HSC $0-\rho_{w} 4$ & 0.004 & $\begin{array}{c}\text { Non-Hybrid } \\
\text { (HSC) }\end{array}$ & 0 & 796 & 610 & 1.3 \\
\hline
\end{tabular}

From the results, it can be seen overrates ultimate loads compared to test results expect B- HS-M-Hy 1- $\rho_{w} 6$ which was cast with $\rho_{w}$ more than the minimum value (0.006) gives ultimate load in experimental higher than modified. The expression gives capacities which are convergent to experimental values for non-hybrid (FHSC) deep beam B-HS-MFHSC $1-\rho_{w} 4$ with SF ratio of $1 \%$. The $\mathrm{X}^{\prime}$ for $\mathrm{P}_{\mathrm{An}} / \mathrm{P}_{\mathrm{Exp}}$ ratio is 1.24 , S.D. is 0.33 and the C.O.V. is 0.27 . These results are shown in Fig. (13).

\subsection{Size Effect on the Capacity of Deep Beams Using the STM}

To investigate the size effect on shear strength of reinforced concrete deep beams, Zhang and Tan in November (2007) [10], carried out an experimental program consisting of three groups of 11 specimens, they noticed that increasing deep beams depth led to decrease in shear strength. They stated that the causes of size effect in deep beams need development, so they submitted that the size effect is influenced by strut geometry and boundary conditions. Zhang and Tan submitted the following modification to Eq. (8) for ultimate shear strength, taking into account the size effect.

$$
V_{n}=\frac{1}{\frac{4 \sin \theta_{S} \cos \theta_{S}}{A_{c} f_{t}}+\frac{\sin \theta_{S}}{v A_{s} t r f_{C}^{\prime}}}
$$

The term $v$ refers to the efficiency factor accounts for the effect of strut geometry, and the effect of strut boundary conditions influenced by web reinforcement. The term $v$ is expressed as follows in Eq. (9) 


$$
v=\xi \times \zeta
$$

where;

$\xi$ : efficiency factor for the effect of strut geometry.

$\zeta$ : efficiency factor for the effect of strut boundary conditions influenced by web reinforcement. These parameters are expressed as follows in Eq. (10 and 11)

$$
\begin{gathered}
\xi=0.8+\frac{0.4}{\sqrt{1+\left(l-w_{s}\right) / 50}} \\
\zeta=0.5+\sqrt{k d_{s} / l_{s}} \leq 1.2
\end{gathered}
$$

Where,

$l$ : length of strut in mm, as shown in Fig. (14).

$d_{s}$ : diameter of web steel bar, when web steel is not provided, $\mathrm{d}_{\mathrm{s}}$ is taken as the minimum diameter of bottom longitudinal steel bars.

$l_{s}$ : maximum spacing of web steel intercepted by the inclined strut, when web steel is not provided, $1_{\mathrm{s}}$ is equal to 1 .

$k=0.5 \times \sqrt{\pi f_{y} / f_{c t}}$ is a material factor, when web steel is not provided, it is taken as half of the above value.

Table 12 summarized the strength of some deep beams of the present investigation which were tested under

\begin{tabular}{|c|c|c|c|c|c|c|}
\hline \multirow[b]{2}{*}{ Beam Designation } & \multirow[b]{2}{*}{$\boldsymbol{\rho}_{w}$} & \multirow[b]{2}{*}{ Type of Beam } & \multirow{2}{*}{$\begin{array}{l}\text { SF } \\
(\%)\end{array}$} & \multicolumn{2}{|c|}{$\begin{array}{c}\text { Ultimate Load }\left(2 V_{n}\right) \\
(k N)\end{array}$} & \multirow{2}{*}{$\mathbf{P}_{\mathrm{An}} \stackrel{\%}{\%}$} \\
\hline & & & & $\begin{array}{c}\text { Modified STM } \\
\text { Zhang and } \\
\text { Tan Article (5.7) }\end{array}$ & Experimental Value & \\
\hline B-HS-M-FHSC 1- $\rho_{w} 4$ & 0.004 & $\begin{array}{l}\text { Non-Hybrid } \\
\text { (FHSC) }\end{array}$ & 1 & 855 & 810 & 1.06 \\
\hline B-HS-M-Hy 1- $\rho_{w} 4$ & 0.004 & Hybrid & 1 & 845 & 730 & 1.16 \\
\hline B- HS-M-Hy $1-\rho_{w} 6$ & 0.006 & Hybrid & 1 & 845 & 900 & 0.94 \\
\hline B-NC-M-Hy 1- $\rho_{w} 4$ & 0.004 & Hybrid & 1 & 680 & 370 & 1.84 \\
\hline B-HS-M-HSC 0- $\rho_{w} 4$ & 0.004 & $\begin{array}{l}\text { Non-Hybrid } \\
\text { (HSC) }\end{array}$ & 0 & 813 & 610 & 1.33 \\
\hline
\end{tabular}
monotonic loading.

Table 12. Comparison between experimental ultimate loads and analytical loads obtained using the modified STM method.

$\mathrm{X}^{\prime}=1.29 \mathrm{SD}=0.35 \mathrm{CV}=0.27$.

The modified STM overrate ultimate loads as compared to test results expect B- HS-M-Hy 1- $\rho_{w} 6$ gives ultimate load in test result higher than modified STM. The expression gives capacity which is convergent value for non-hybrid (FHSC)deep beam B-HS-M-FHSC $1-\rho_{w} 4$ only. The $\mathrm{X}^{\prime}$ for $\mathrm{P}_{\mathrm{An}} / \mathrm{P}_{\mathrm{Exp}}$ ratio is $1.29, \mathrm{SD}$ is 0.35 and the $\mathrm{CV}$ is 0.27 . These results are shown in Fig. (14).

\subsection{Assumptions of Three Methods for Strut and Tie Model Used in the Present Work}

1. They assumed that for beams in which bearing and anchorage failures at the nodes are prevented, shear capacity is governed by the compressive capacity of the strut and the mean stress in the strut depends on its dimensions. The strut is assumed to have a uniform width (prismatic strut) defined by geometry of the node at the support.

2. A simple truss model and the resulting failure are resultant of crushing failure of concrete in diagonal strut and tensile failure by splitting of concrete along diagonal strut and yielding of reinforcement.

3. The arch action after the formation of diagonal cracks where it adversely affects the shear strength as the depth becomes larger. 

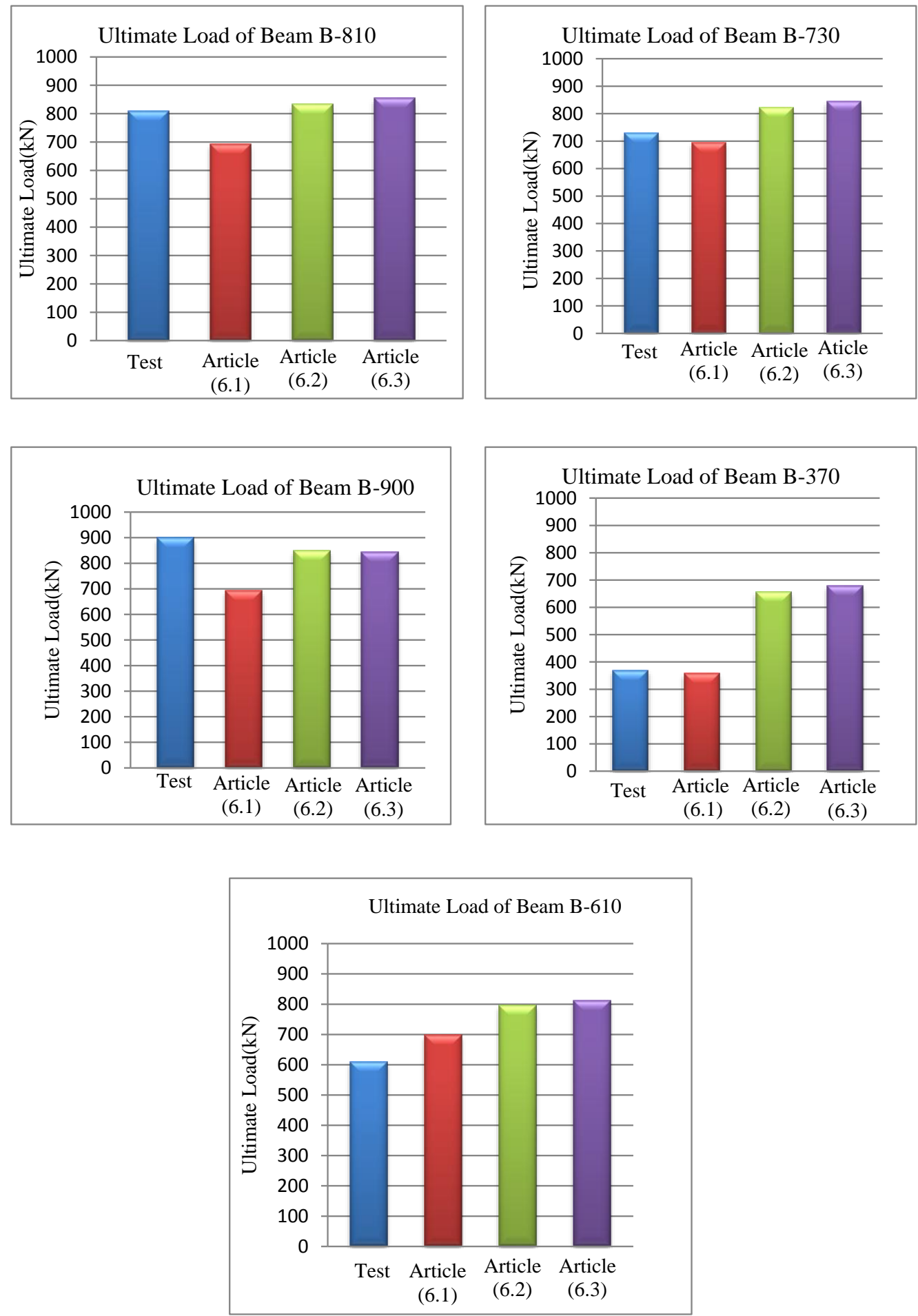

Fig. (14). Comparison between ultimate loads obtained using different experimental and analytical methods.

\section{CONCLUSION}

\section{Experimental Stage}

In a general manner, the ultimate loads of deep beams subjected to repeated loading ( $75 \%$ of their conforming monotonic loading per cycle) are least than the ultimate loads of conforming beams tested under monotonic loading in the ranges of variables adopted in the present work, as follows: 
a. The decreased percentages in the ultimate load according to repeated loading for non-hybrid deep beams of HSC and FHSC are approximate which are $22.95 \%$ and $20.98 \%$, respectively.

b. The decreased percentages in the ultimate load according to the repeated loading of hybrid deep beams which have web reinforcement $(0.004$ and 0.006$)$ as variable are approximate which are $23.97 \%$ and $22.22 \%$, respectively.

c. The decreased percentage in the ultimate load according to the repeated loading of hybrid deep beams with compressive strength concrete (high and normal) as variable is approximate which are $23.97 \%$ and $24.32 \%$, respectively.

d. The average value of the decreased percentage of beams subjected to monotonic and $75 \%$ repeated loading is $22.17 \%$.

1. The ultimate load of beam increases with existence SF, for beam tested under monotonic load. The increase for beam cast from FHSC (SF 1\%) is 32.79\% and for the hybrid beam (SF 1\% in shear span only), it increases by $19.67 \%$ as compared with non- hybrid beam cast from HSCC. The increase in ultimate load of FHSC deep beam is $10.96 \%$ as compared with hybrid beam.

2. It was found that the hybrid beam (SF 1\%) in shear span only and non-hybrid beam cast from FHSC (SF 1\%) fails under repeated loading in load higher than non-hybrid beam cast from HSC by $18.09 \%$ and $36.17 \%$, respectively. While beam which was cast with FC (SF1\%) fails in load higher than the hybrid beam by $15.32 \%$.

3. The ultimate load of HSC of beams tested under monotonic loading is $97.3 \%$ for hybrid beam higher than of an identical NSC. Therefore, the concrete compressive strength significantly effects on the capacity of the tested beam. In repeated loading, the increasing of the ultimate load for HSC beam is $98.21 \%$ as compared with NSC.

4. The ultimate load for HSC beams which are tested under monotonic loading increases by $28.07 \%$ and $57.89 \%$ when the web reinforcement $\boldsymbol{\rho}_{w}$ increases from (0-0.004) and (0-0.006), respectively. Furthermore, it was noticed that when testing such kind of beams under a repeated loading leads to an increase in the ultimate load from $26.16 \%$ to $59.09 \%$, respectively as the ratio of increased from (0-0.004) and from (0-0.006), respectively.

\section{Analytical Stage}

1. Results of the ultimate loads of ACI 318R-14 are conservative values as compared to the conforming experimental ones, but it can be noticed that the STM underestimates the load capacity for some beams and overestimates for others. The average amount $\left(\mathrm{X}^{\prime}\right)$ for the analytical/test ratio of ultimate loads $\left(\mathrm{P}_{\mathbf{A n}} / \mathrm{P}_{\mathbf{E x p}}\right)$ is 0.94 , the standard deviation (SD) is 0.14 and the coefficient of variation (CV) is 0.15 .

2. The modified STM developed by Zhang and Tan in March 2007 overrates the ultimate loads as compared to test results expect B-HS-M-Hy $1-\rho_{\mathrm{w}} 6$ gives in test result higher than modified STM. The $\mathrm{X}^{\prime}$ is 1.24 , SD is 0.33 and the $\mathrm{CV}$ is 0.27 .

3. The modified STM developed by Zhang and Tan in November 2007, that includes the effect of size factor, overrate ultimate loads as compared to test results expect B-HS-M-Hy $1-\rho_{\mathrm{w}} 6$ given in test results higher than the modified STM. The $\mathrm{X}^{\prime}$ is $1.29, \mathrm{SD}$ is 0.35 and the $\mathrm{CV}$ is 0.27 .

\section{CONSENT FOR PUBLICATION}

Not applicable.

\section{CONFLICT OF INTEREST}

The authors declare no conflict of interest, financial or otherwise.

\section{ACKNOWLEDGEMENTS}

Declared none.

\section{REFERENCES}

[1] ACI Committee 318R, Building Code Requirement for Structural Concrete and Commentary, American Concrete Institute: Farmington Hills, Michigan, 2014.

[2] M. Shahnewaz, "Shear Behavior of Reinforced Concrete Deep Beam under Static and Dynamic Load", M.SC. Thesis, University of British 
Columbia, Vancouver, British Columbia, Canada, 2013.

[3] K. Mohamaed, A. S. Farghaly, and B. Benmokran, "Proposed Strut and Tie Model for Concrete Deep Beams Reinforced with FRP Bars", M.SC. Thesis, Université de Sherbrooke, Canada, 2016.

[4] P. Foraboschi, "Shear strength computation of reinforced concrete beams strengthened with composite materials", Comp. Mech. Comput. Appl. Int. J., vol. 3, no. 3, pp. 227-252, 2012.

[5] P. Foraboschi, "Analytical model to predict the lifetime of concrete members externally reinforced with FRP", Theor. Appl. Fract. Mech., vol. 75, no. 1, pp. 137-145, 2015. [http://dx.doi.org/10.1016/j.tafmec.2014.12.002]

[6] P. Foraboschi, "Predictive multiscale model of delayed debonding for concrete members with adhesively bonded external reinforcement", Comp. Mech. Comput. Appl. Int. J., vol. 3, no. 4, pp. 307-329, 2012.

[http://dx.doi.org/10.1615/CompMechComputApplIntJ.v3.i4.20]

[7] D. Birrcher, R. Tuchscherer, M. Huizinga, O. Bayrak, S. Wood, and J. Jirsa, "Strength and serviceability design of reinforced concrete deep beams", CTR Technical Report, December, 2008.

[8] N. Zhang, and K.H. Tan, "Predictive multiscale model of delayed debonding for concrete members with adhesively bonded external reinforcement", Sci. Direct Eng. Struct. J., vol. 29, pp. 2987-3001, 2007.

[http://dx.doi.org/10.1016/j.engstruct.2007.02.004]

[9] K.H. Tan, and H.K. Lu, "Shear Behavior of Large Reinforced Concrete Deep Beams and Code Comparisons", ACI J., vol. 96, no. 5, pp. 836-845, 1999.

[10] N. Zhang, and K.H. Tan, "Size Effect in RC Deep Beams: Experimental Investigation and STM Verification", Sci. Direct Eng. Struct. J., vol. 29, pp. 3241-3254, 2007.

[http://dx.doi.org/10.1016/j.engstruct.2007.10.005]

(C) 2018 Hassan and Mhebs.

This is an open access article distributed under the terms of the Creative Commons Attribution 4.0 International Public License (CC-BY 4.0), a copy of which is available at: (https://creativecommons.org/licenses/by/4.0/legalcode). This license permits unrestricted use, distribution, and reproduction in any medium, provided the original author and source are credited. 